\title{
Conservation Agriculture Enhances Soil Fauna Richness and Abundance in Low Input Systems: Examples From Kenya
}

\author{
Fredrick Ouma Ayuke ${ }^{1,2 *}$, Job Kihara ${ }^{3}$, George Ayaga ${ }^{4}$ and Alfred N. Micheni ${ }^{5}$ \\ 1 Department of Land Resource Management and Agricultural Technology (LARMAT), University of Nairobi, Nairobi, Kenya, \\ ${ }^{2}$ Rwanda Institute for Conservation Agriculture (RICA), Kigali, Rwanda, ${ }^{3}$ International Centre for Tropical Agriculture CIAT, \\ ICIPE Duduville Complex, Nairobi, Kenya, ${ }^{4}$ Kenya Agricultural and Livestock Research Organization-KALRO, Busia, Kenya, \\ ${ }^{5}$ Kenya Agricultural and Livestock Research Organization-KALRO, Embu, Kenya
}

OPEN ACCESS

Edited by:

Philippe C. Baveye,

AgroParisTech Institut des Sciences et Industries du Vivant et de L'environnement, France

Reviewed by: Achouak Arfaoui, University of Jendouba, Tunisia Joerg Roembke, ECT Oekotoxikologie, Germany

${ }^{*}$ Correspondence:

Fredrick Ouma Ayuke fredrick.ayuke@yahoo.com

Specialty section: This article was submitted to

Soil Processes,

a section of the journa

Frontiers in Environmental Science

Received: 22 February 2019 Accepted: 07 June 2019

Published: 28 June 2019

Citation:

Ayuke FO, Kihara J, Ayaga G and Micheni AN (2019) Conservation Agriculture Enhances Soil Fauna Richness and Abundance in Low Input Systems: Examples From Kenya. Front. Environ. Sci. 7:97. doi: 10.3389/fenvs.2019.00097
Conservation agriculture (CA) (zero tillage + organic inputs as surface residue) is believed to improve soil nutrient status, soil structure, control soil erosion, and also enhance soil fauna diversity. Despite the widespread interest in CA, empirical evidence of the benefits of CA on soil fauna diversity is limited, especially in low-input systems of sub-Saharan Africa (SSA). Consequently, the magnitude and effect by CA on soil fauna remains unquantified. The aim of this study was to evaluate the effect of CA and associated management practices on soil fauna richness and abundance. We hypothesized that $\mathrm{CA}$ and mixed cropping would positively influence soil fauna richness and abundance. We compared CA with conventional till (CT; with or without residues) in sole maize and maize-bean cropping systems. Soil macrofauna and mesofauna were sampled across the treatments in medium-term (6 years) trials in Embu, Central Kenya, and Kakamega (6 years) and a long-term trial in Nyabeda (15 years) using soil monoliths and core samplers, respectively. In agreement with our hypothesis, higher macrofauna taxonomic richness and mesofauna was recorded in CA than in CT without residues. This study demonstrated that: (1) medium to long-term addition of organic residues enhances soil fauna richness and abundance, (2) CA increases soil fauna taxonomic richness and abundance compared with CT, and (3) CA under maize-bean intercropping, rotation and sole maize cropping systems promote soil fauna richness and abundance compared with sole legume (common beans). We conclude that adoption of CA is important in enhancing richness of soil fauna. Given the numerous challenges faced by smallholder farmers of SSA in the adoption of CA, who in most cases rarely practice all the three CA principles simultaneously, we propose a further study that will determine the effects and interactions between each of the CA components on soil fauna richness and abundance.

Keywords: tillage, organic resources, soil fauna, richness, abundance 


\section{INTRODUCTION}

Conservation agriculture (CA), which encompasses minimum soil disturbance, soil cover, and crop diversification as its three main principles [with a fourth principle on fertilizer application being recently suggested by Vanlauwe et al. (2014)], has been successfully promoted in different parts of the world such as the temperate zone and parts of Latin America (Lal, 2007; Wall, 2007; Derpsch et al., 2010). Despite its low adoption in sub-Saharan Africa (SSA), the rapidly changing demographics in the region including a transformation of its economies to middle class, and the ongoing large initiatives to promote CA present opportunities of increasing its adoption. As such, evidence is needed around the various sustainability indicators of CA including soil biological indices (Ayuke et al., 2011a,b; Paul et al., 2015). Indeed, CA has been shown to stimulate soil fauna that play important role in soil aggregation, soil C sequestration, soil nutrient and water use efficiencies, and influence crop yields (Nhamo, 2007; Castellanos-Navarrete et al., 2012; Paul et al., 2015).

In many parts of the world, especially areas of SSA, the challenge of feeding an ever increasing population is persistent, due to prevalent land degradation and low soil productivity. Farmers' efforts to restore and maintain soil fertility are constrained by various challenges, the major ones being accessibility, affordability and knowledge on input management (Karanja et al., 2006; Vanlauwe et al., 2015). Historically, increasing food production in Africa has largely been attributed to land intensification and there has been efforts to intensify by increasing productivity per unit area. Sustainable intensification (SI) attempts to promote increased crop productivity by small-holder farmers in SSA (Garnett et al., 2013). Although SI has addressed the yield component, other aspects of sustainability such as soil biological functions have not been sufficiently addressed. SI advocates for management practices that reconcile environmental conservation and sustainability, and food security (Brussaard et al., 2010).

Despite the widespread interest in CA, empirical evidence of the benefits of CA in SSA is limited (Paul et al., 2013). For instance, the magnitude and direction of effect by $\mathrm{CA}$ on soil fauna, however, remains unquantified, especially in low-input systems of Sub-Saharan Africa. Response of soil fauna to soil tillage, available crop residues, and cropping practices in the region is largely unclear yet such knowledge is imperative for environmental conservation, sustainability and improved ecosystem services. Therefore, the aim of this study was to evaluate the effect of CA and associated management practices on soil fauna richness and abundance. Specifically, the study was to assess how conservation agriculture and its principal elements that encompass zero tillage, application of organic or inorganic inputs and cropping system, affect soil fauna richness and abundance. It is hypothesized that $\mathrm{CA}$, organic or inorganic inputs and crop rotation and or mixed cropping would positively influence soil fauna richness and abundance.

\section{MATERIALS AND METHODS}

\section{Study Sites}

The studies were conducted at three sites (Plate 1). The first included a medium-term (6 years) trial, based at the Kenya Agricultural and Livestock Research Institute (KALRO) in Embu County, about $130 \mathrm{~km}$ north of Nairobi, Kenya. The trial is located in the sub-humid Central highlands of Kenya on the southern slopes of Mt Kenya at: latitude $0^{\circ} 32^{\prime} \mathrm{S}$, longitude $37^{\circ} 37^{\prime} \mathrm{E}$ and an altitude of $1,480 \mathrm{~m}$ (Table 1). The average temperature is $19.5^{\circ} \mathrm{C}$. The area receives bimodal rains with a mean total of 1,450 $\mathrm{mm}$ in two distinct seasons: long rains (March to August) and short rains (October to January). Agroecological zone is Upper mid land (UM3) (Jaetzold et al., 2007). The Soils are mainly Humic Nitisols (FAO, 1989) derived from basic volcanic rocks (FAO-UNESCO, 1997). They are deep, wellweathered with a clay texture (\% sand, clay, silt: 3,22 , and 75 ) with moderate to high inherent fertility. The second is a medium-term trial (6 years) based at the Kenya Agricultural and Livestock Research Institute (KALRO) Kakamega (also in sub-humid western Kenya, Kakamega County), while the third is Nyabeda, a sub-humid site in western Kenya, within Siaya County where a long-term trial (15 years) is located. The Kakamega and Nyabeda sites are characterized by two rainy seasons: a long rainy season between March and August and short rainy season between September and January (Jaetzold et al., 2007). In all the sites, maize is the main staple crop and is normally grown either as a monocrop or in association with legumes, mainly common beans and groundnuts. Soybean, a cash crop, is also grown by farmers in the western Kenya region. All sites have predominantly smallholder settlements, with land sizes ranging from 0.3 to 3 ha per household. The study sites represent different soil types with varied physical and chemical characteristics. The study was conducted in December 2015 for the sites in eastern Kenya and June-July 2016 for the two trials in western Kenya.

\section{Experimental Design \\ Embu Trial}

The medium-term (6 years) field trial was established in 2010. Treatments tested for soil fauna include tillage (conventional till: CT, zero till: CA), organic residues (maize or bean residues: $\mathrm{CR}$ ) and cropping systems (sole maize: SM, sole bean: SB and maize-bean intercrop: MBi) (Table 2). During the cropping seasons, plots are planted with maize (Zea mays Hybrid 512) and beans (Phaseolus vulgaris, variety Rose Coco) as per treatments. Mineral N fertilizer is applied targeting $60 \mathrm{~kg} \mathrm{~N} \mathrm{ha}^{-1}$ for sole maize (SM) and $20 \mathrm{~kg} \mathrm{~N} \mathrm{ha}^{-1}$ for sole beans (SB), applied as calcium ammonium nitrate (CAN), one-third at planting, and two-third at stage V6 of maize. Maize-bean intercrop (MBi) received $80 \mathrm{~kg} \mathrm{~N} \mathrm{ha}^{-1}$. Irrespective of tillage methods, $\mathrm{SM}, \mathrm{SB}$, and $\mathrm{MBi}$ received 60, 51, and $111 \mathrm{~kg} \mathrm{P}_{2} \mathrm{O}_{5} \mathrm{ha}^{-1}$ from [N23P23], [N18P46], and combination of [N23P23] + [N18P46] fertilizer materials, respectively (Micheni et al., 2016). For the treatments receiving organic inputs, all residues from the preceding crop were incorporated into the soil, thus providing about $39.2 \mathrm{t} \mathrm{C}$ 


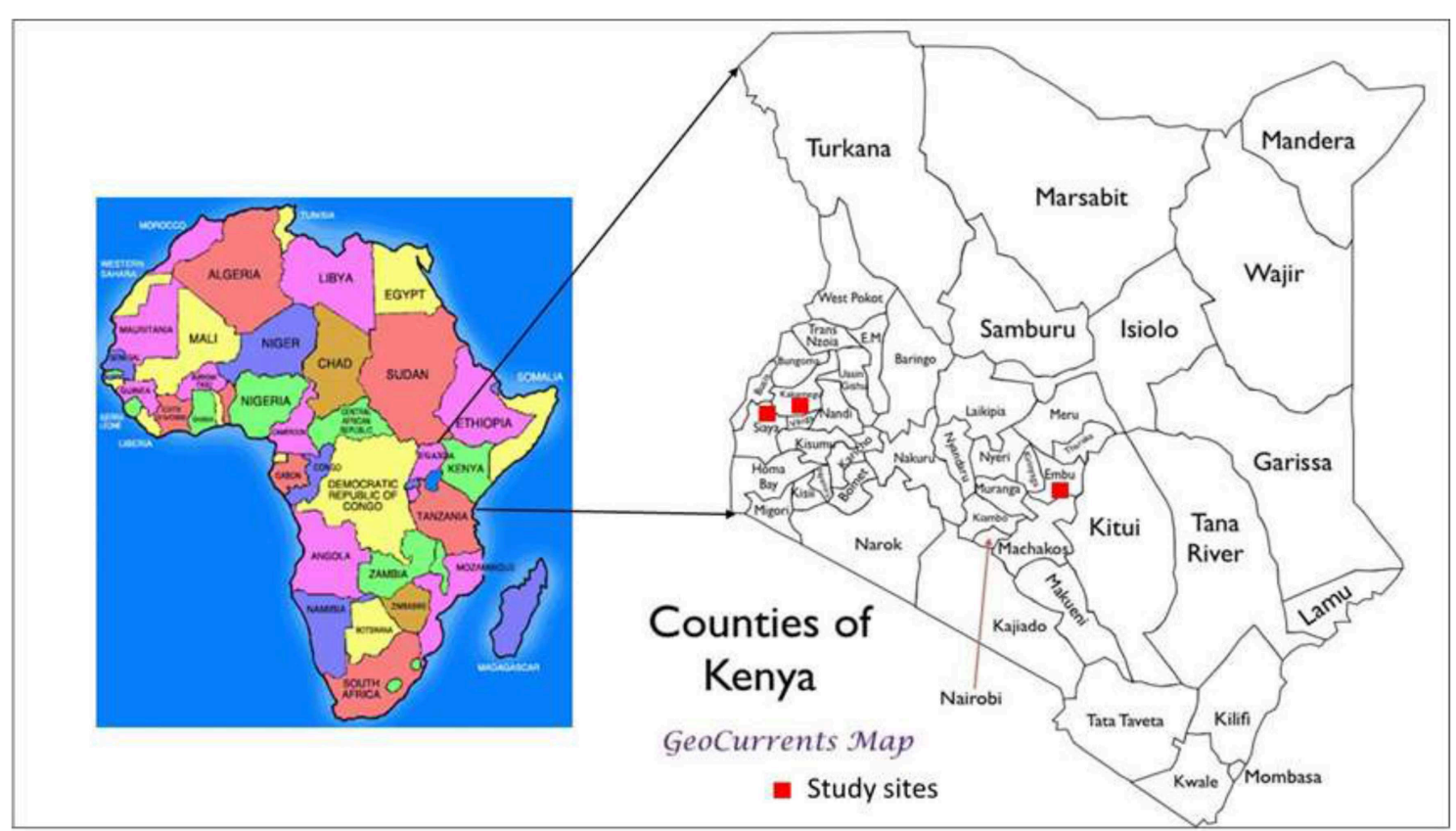

PLATE 1 | Map showing location of the study sites.

$\mathrm{ha}^{-1}$ and $67.4 \mathrm{t}$ of SOM, respectively. Residues were removed from those treatment not receiving residues. The treatments were replicated three times in a randomized complete block design with plots of $10 \mathrm{~m}$ long by $8 \mathrm{~m}$ wide. Conventional till was done by hand-hoeing to a maximum depth of $15 \mathrm{~cm}$, whereas no tillage was conducted in the zero till plots. Sole maize (SM): Maize spacing was $75 \mathrm{~cm}$ between rows and $50 \mathrm{~cm}$ within. Three seeds were sown per hill and thinned 1 week after crop emergence to two plants per hill, to give a plant population of 53,333 plants $\mathrm{ha}^{-1}$. Sole bean (SB): Sole bean were spaced at $50 \mathrm{~cm}$ between rows and $15 \mathrm{~cm}$ within rows while maintaining one plant per hill giving plant population of 133,330 plants ha ${ }^{-1}$. Maize bean intercrop (MBi): Maize spacing was maintained like in maize sole crop but bean spacing was slightly adjusted to $50 \mathrm{~cm}$ between rows and $20 \mathrm{~cm}$ within rows and two plants per hill. This gave plant population of 133,330 plants $\mathrm{ha}^{-1}$, which was the same as in SB configuration. This was done to minimize confounding effects due to plant population differences (Micheni et al., 2016). Under CT, two weed control events were conducted manually using hand tools (machete and hoes) within a given season. The first weeding was done 1-2 weeks after crop emergence and the second was conducted in approximately one and half months after the first weeding. In the CA treatments, weeds were controlled using pre and post-emergence herbicides. Roundup (Glyphosate), a post-emergence herbicide, was applied at the rate of 3.0 liters (L) ha ${ }^{-1}$ to kill weeds at the beginning of the seasons. Dual Gold (960 $\mathrm{g} \mathrm{L}^{-1}$ Metolachlor), a pre-emergence herbicide, was applied at the rate of $2.0 \mathrm{~L} \mathrm{ha}^{-1}$ on relatively moist soil surface after planting but before emergence of crops and weeds. One month after the crop emergence, selective Basagran post-emergence herbicide was applied at the rate of $2.0 \mathrm{Lha}^{-1}$ to manage actively growing grass and broad-leafed weeds in maize-bean intercrop.

The herbicide is effective mainly through contact action and therefore care was taken to have all weeds thoroughly covered with the herbicide sprays while avoiding maize and bean leaves.

\section{Kakamega}

The experimental set up, design and management of this trial was the same as that of Embu medium-term. The trial tested the effect of different treatments on arable crop production and these include: tillage (conventional till, zero till), organic (maize residues) and cropping systems (continuous maize, maize-bean rotation and intercrop; Table 2). However, fertilizer was applied at a rate of $50 \mathrm{~kg} \mathrm{~N} \mathrm{ha}^{-1}$ and $25 \mathrm{~kg} \mathrm{P} \mathrm{ha}^{-1}$. The organic inputs are applied onto the soil surface every season at $2 \mathrm{t} \mathrm{ha}^{-1}$. The residues, however, were removed from those treatment not receiving residues. The treatments were replicated three times in a randomized complete block design with plots of $10 \mathrm{~m}$ long by $8 \mathrm{~m}$ wide. Treatments selected for soil fauna studies included: maize-bean intercrop (MBi) under conventional (CT) and zero (CA) till, but all with crop residues (CR) applied. A no input treatment that typically represented farmer practice (or control) was also sampled (Table 2).

\section{Nyabeda Trial}

The field experiment was established in March 2003, and has been managed by the International Center for Tropical Agriculture (CIAT). The details of the trial set-up and management are documented in Kihara et al. (2012). The treatments used to study soil fauna diversity include a farmer practice under sole maize, CT with residues added, CA under maize-soybean 
TABLE 1 | Location, climatic, and soil characteristics of the study sites.

\begin{tabular}{|c|c|c|c|}
\hline Parameter & Embu & Kakamega & Nyabeda \\
\hline Year established & MT-2010 & MT-2010 & LT-2003 \\
\hline Agro-climatic zone & Humid & Sub-humid & Sub-humid \\
\hline Agro-ecological zone & Upper midland 3 & Upper midland 1 & lower midland 2 \\
\hline Latitude & $00^{\circ} 33.18^{\prime} \mathrm{S}$ & $0^{\circ} 16.96^{\prime} \mathrm{N}$ & $0^{\circ} 07^{\prime} \mathrm{N}$ \\
\hline Longitude & $037^{\circ} 53.27^{\prime} \mathrm{E}$ & $3446.07^{\prime} \mathrm{E}$ & $34^{\circ} 24^{\prime} \mathrm{E}$ \\
\hline Altitude (m.a.s.l.) & 1,420 & 1,534 & 1,420 \\
\hline Total annual rainfall (mm) & 1,250 & 1,978 & $1,800^{\mathrm{a}}$ \\
\hline \multicolumn{4}{|l|}{ Daily temperatures $\left({ }^{\circ} \mathrm{C}\right):$} \\
\hline Mean & 20 & 21 & 23.2 \\
\hline Minimum & $16-21$ & 11 & 14 \\
\hline Maximum & $21-28$ & 26 & 31 \\
\hline Soil type & Humic Nitisols ${ }^{b}$ & Eutric Nitisol ${ }^{\mathrm{C}}$ & Ferralsol $^{\mathrm{C}}$ \\
\hline Sand:silt:clay ratio & $3: 22: 75$ & $13: 34: 53$ & $15: 21: 64$ \\
\hline $\mathrm{pH}$ (water) & 3.88 & 5.40 & 5.08 \\
\hline Extractable $\mathrm{K}$ (me $100 \mathrm{~g}^{-1}$ ) & 0.27 & 0.70 & 0.10 \\
\hline$P\left(\mathrm{mg} \mathrm{P} \mathrm{kg}^{-1}\right)$ & 16.13 & 3.40 & 2.99 \\
\hline $\mathrm{Ca}\left(\mathrm{cmolc} \mathrm{kg}^{-1}\right)$ & 2.15 & 0.93 & $4.69^{\star}$ \\
\hline $\mathrm{Mg}\left(\mathrm{cmolc} \mathrm{kg}^{-1}\right)$ & 0.45 & 0.05 & $1.68^{\star}$ \\
\hline Total SOC (\%) & 3.70 & 4.10 & 1.35 \\
\hline Total Nitrogen (\%) & 0.37 & 0.30 & 0.15 \\
\hline
\end{tabular}

*Value obtained in meq $100 \mathrm{~g}^{-1}$ of soil.

a 2002-2008 period.

${ }^{b}$ See Jaetzold et al. (2007) for details.

'See Jaetzold et al. (2006) for details.

MT, medium-term; LT, long-term.

rotation and intercropping. There were 3 replicates included and individual plots measured $7 \times 4.5 \mathrm{~m}$. The crop rotation since trial establishment consisted of soybean (Glycine max L.) during short rains and maize (Zea mays L.) during long rains. All plots were fertilized with $60 \mathrm{~kg} \mathrm{ha}^{-1} \mathrm{~N}$ (urea), $60 \mathrm{~kg} \mathrm{ha}^{-1} \mathrm{P}$ (Triple Super Phosphate), and $60 \mathrm{~kg} \mathrm{ha}^{-1} \mathrm{~K}$ (Muriate of Potash) per season (Table 2). To control stem borer, $5 \mathrm{~kg} \mathrm{ha}^{-1}$ of granulated Bulldock (beta-cyfluthrin) was applied in the funnel of the maize plants during the 5 th week after planting in all treatments. Under CT, the seedbed was prepared by hand-hoeing to $15 \mathrm{~cm}$ soil depth. Weeding was performed three times per season using hand hoe. Under CA, a $3 \mathrm{~cm}$ deep seedbed was prepared with the hand hoe. Weeding was performed three times per season by hand pulling until the long rainy season of 2009. Thereafter, herbicides (glyphosate and 2, 4-dichlorophenoxyacetic acid) have been applied to all CA treatments before planting and subsequent weeding done by hand pulling. Maize residues were collected after crop harvest, dried, chopped and stored during the dry season. At the time of soybean planting, the residues were reapplied at a rate of $2 \mathrm{~h} \mathrm{ha}^{-1}$ for those treatments receiving crop residues. Since soybeans drop leaves prior to grain maturity, soybean residues (leaves and stems) always remained in the field after harvesting, irrespective of treatment. These soybean residues were then either incorporated in CT or remained at the soil surface in CA. In our fauna sampling regime, only a few of the trial treatments were selected, and a no input treatment was also sampled as in Kakamega (Table 2).

\section{Faunal Sampling Techniques}

Two techniques were employed to sample fauna for richness and abundance.

\section{Macrofauna}

Using a monolith of size $25 \mathrm{~cm} \times 25 \mathrm{~cm} \times 30 \mathrm{~cm}$, samples were taken 8 weeks (in December 2015 for the sites in eastern Kenya and June-July 2016 two experimental trials in western Kenya) after planting crops in the season (Swift and Bignell, 2001; Bignell et al., 2008): At each observation, one sample was taken randomly from each plot. The monolith was situated over a randomly selected spot and dug with a spade and hoe to a $30 \mathrm{~cm}$ soil depth (Plate 2). The soil from the monolith was removed by hand depth-wise $(0-15$ and $15-30 \mathrm{~cm})$ into plastic buckets. The soil sample from each depth was placed in different plastic trays $(20 \mathrm{~cm}$ by $30 \mathrm{~cm})$ and gently sorted out to locate the animals. The animals were separated into major taxonomic groups, recorded and then collected in plastic bottles. The soil fauna collected were preserved in $75 \%$ alcohol for subsequent identification at the Soil microbiology laboratory of CIAT, ICIPE Duduville Campus, Nairobi, Kenya. Earthworms were killed in 75\% alcohol and fixed in $4 \%$ formaldehyde. In the laboratory, counting was done. Species richness, and number of different categories of animals were expressed per meter square.

\section{Mesofauna}

At the same time of sampling for macrofauna soil samples were collected for mesofauna observations using a metallic core of $10 \mathrm{~cm}$ diameter up to $30 \mathrm{~cm}$ depth (and at same $0-15$ or $15-$ $30 \mathrm{~cm}$ depths as macrofauna). One sample was taken in each plot at each sampling. The samples were taken to the CIAT laboratory where mesofauna groups were extracted using the behavioral or dynamic method with Berlese-Tullgren as the basic apparatus (Plate 3) (Southwood, 1995). This apparatus was originally designed by an Italian entomologist, Berlese, A. and later modified by a Swede, Tullgren, A. who used a light bulb as the source of heat. The apparatus has since been modified by many workers (Southwood, 1995). For this study the apparatus was designed and constructed locally.

Basically, the collected soil was poured into the perforated soil sample containers of the "Berlese-Tullgren" funnel apparatus over a funnel. Heat was applied to the soil using a 75 watts bulb placed above the sample container. Heat supplied was regulated by upward adjustments of the sample containers. Thus, the animals were exposed to a controlled gradient of high to low temperature and light, and low to high humidity from top to bottom, so that the animals are driven gradually downwards and out into the collection jars filled with $75 \%$ alcohol. The set up was left for $24 \mathrm{~h}$. After this period, the animals collected in the jars were sorted out and counted under a light microscope. The preserved animals were also stored and later taken to the laboratory for taxonomic analyses.

\section{Soil Sampling and Nutrient Analysis}

Immediately after handpicking the soil macrofauna, soils from each monolith was mixed thoroughly to make 
TABLE 2 | Treatment selected and descriptions.

\begin{tabular}{|c|c|c|c|c|}
\hline Treatment & Tillage & Cropping & Organic input & Inorganic input \\
\hline \multicolumn{5}{|c|}{ Embu medium-term trial } \\
\hline 1. CTMBi-CR & Conventional & Maize-beans intercrop & None & $80 \mathrm{~kg} \mathrm{~N}, 111 \mathrm{P}_{2} \mathrm{O}_{5}$ \\
\hline 2. $\mathrm{CASB}+\mathrm{CR}$ & Zero & Sole beans & Beans residues & $20 \mathrm{~kg} \mathrm{~N}, 51 \mathrm{~kg} \mathrm{P} \mathrm{O}_{5}$ \\
\hline 3. $\mathrm{CASM}+\mathrm{CR}$ & Zero & Sole maize & Maize residues & $60 \mathrm{~kg} \mathrm{~N}, 60 \mathrm{~kg} \mathrm{P} \mathrm{O}_{5}$ \\
\hline 4. $\mathrm{CAMBi}+\mathrm{CR}$ & Zero & Maize-beans intercrop & Maize and beans residues & $80 \mathrm{~kg} \mathrm{~N}, 111 \mathrm{P}_{2} \mathrm{O}_{5}$ \\
\hline \multicolumn{5}{|c|}{ Kakamega medium-term trial } \\
\hline 1. FP (Farmer practice) & Conventional & Sole maize & None & None \\
\hline 2. $\mathrm{CTMBi}+\mathrm{CR}$ & Conventional & Maize-bean intercrop & 2 t/ha maize residues & $50 \mathrm{~N}, 25 \mathrm{P}$ \\
\hline 3. $\mathrm{CAMBi}+\mathrm{CR}$ & Zero & Maize-bean intercrop & 2 t/ha maize residues & $50 \mathrm{~N}, 25 \mathrm{P}$ \\
\hline \multicolumn{5}{|l|}{ Nyabeda long-term trial } \\
\hline 1. FP (Farmer practice) & Conventional & Sole maize & None & None \\
\hline 2. $\mathrm{CTMSr}+\mathrm{CR}$ & Conventional & Maize-soybean rotation & 2 t/ha maize residues & $60 \mathrm{~kg} \mathrm{~N} /$ ha-Urea \\
\hline 3. $\mathrm{CAMSr}+\mathrm{CR}$ & Zero & Maize-soybean rotation & 2 t/ha maize residues & $60 \mathrm{~kg} \mathrm{~N} /$ ha-Urea \\
\hline 4. $\mathrm{CAMSi}+\mathrm{CR}$ & Zero & Maize-soybean intercrop & 2 t/ha maize residues & $60 \mathrm{~kg} \mathrm{P} / \mathrm{ha}-\mathrm{TSP}$ \\
\hline
\end{tabular}

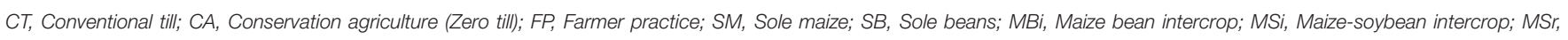
Maize-soybean rotation $C R$, Crop residue; N, Nitrogen; +/-denotes with or without crop residues and with or without nitrogen.

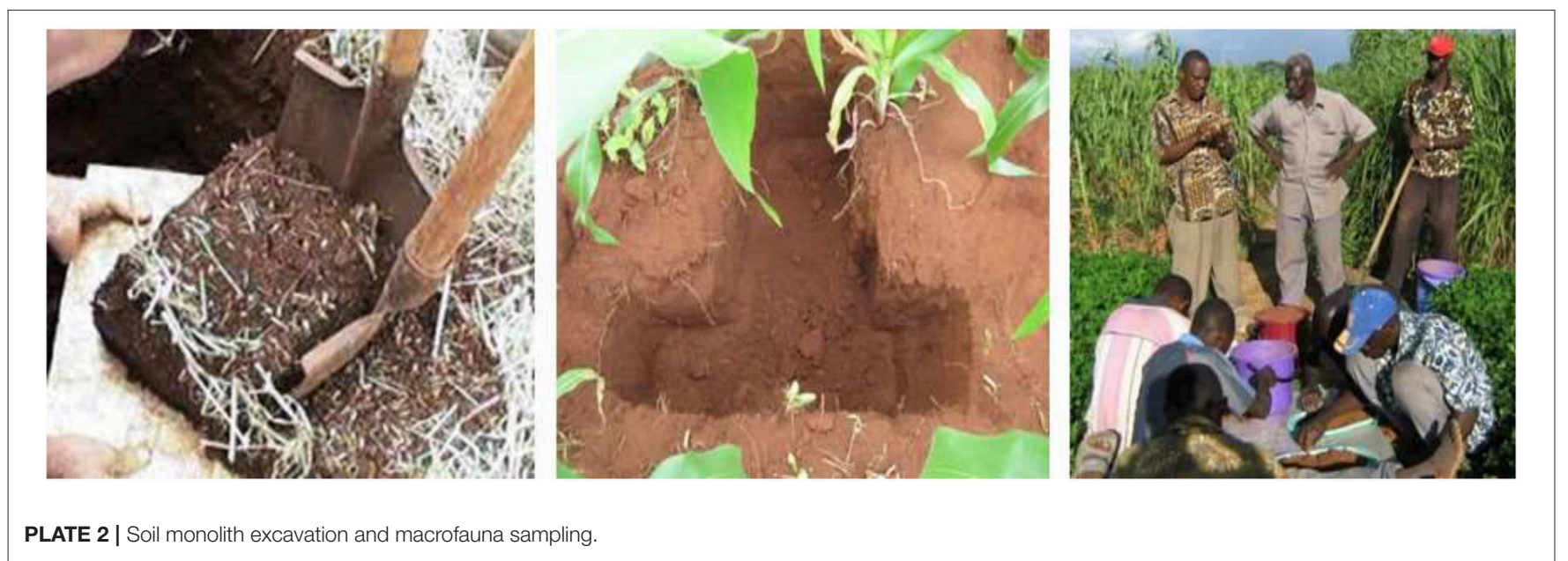

a composite sample of about $500 \mathrm{~g}$ for analysis. Soil parameters measured included: soil $\mathrm{pH}$ total organic $\mathrm{C}$ and $\mathrm{N}$, available $\mathrm{P}$, and exchangeable bases $(\mathrm{Na}, \mathrm{K}, \mathrm{Ca}$, and $\mathrm{Mg}$ ). Soil $\mathrm{pH}$ was determined using a $\mathrm{pH}$ meter with soil-water ratio of 1:2.5 (Anderson and Ingram, 1993). Total organic $\mathrm{C}$ and $\mathrm{N}$ were determined using a $\mathrm{CN}$ analyser, while $\mathrm{P}$ and the bases were extracted by the Mehlich-3 procedure (Mehlich, 1984) and measured through inductively coupled plasma atomic emission spectroscopy (Isaac and Johnson, 1998).

\section{Statistical Analyses}

The data obtained on soil fauna richness and abundance and soil chemical properties were subjected to analysis of variance (ANOVA) with Genstat 17.1 (2015). Levene's test was used to test for homogeneity of variances (Field, 2005). In case of non-homogeneity of variances, data were square root $(x+$ $0.5)^{1 / 2}$ transformed before further analysis. Fauna data were analyzed separately for each depth $(0-15$ and $15-30 \mathrm{~cm})$. Linear Mixed Model was fitted by Restricted Maximum Likelihood (RELM) procedure using the Genstat package. This procedure allows for inclusion of both fixed- and random-effects terms in the model such that profiled deviance of RELM criterion is optimized for the parameter estimates (Kuznetsova et al., 2014; Bates et al., 2015). Treatments were included in the model as fixed factors, whereas block was defined as a random factor. The statistical significance was determined at $p \leq 0.05$ and levels of significance among the different treatments were evaluated using Fischer's least significance difference (LSD). Correlation analysis (Pearson correlations), was conducted to establish the significance of the relationships between soil fauna and soil factors. Because fauna and soil variables had different units of measurement, they were standardized first so that each variable received equal weight in the analysis and also to make the coefficient (r) values comparable (Cao et al., 1999; Jongman et al., 2005). 


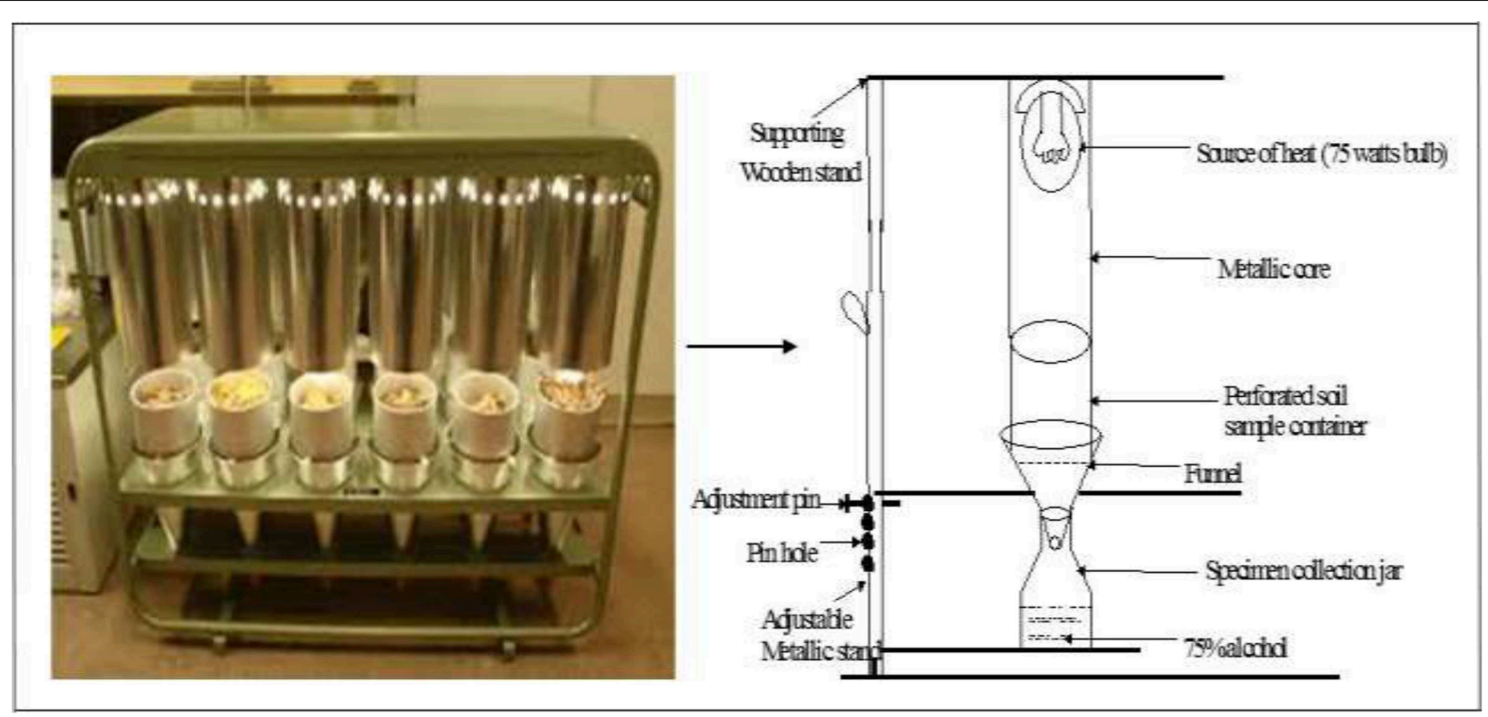

PLATE 3 | Photo and sketch diagram showing the Berlese-Tullgren apparatus.

\section{RESULTS}

\section{Soil Fauna Composition}

Overall, a total of 58 macrofauna species classified into 14 major groups were sampled across the three trials in eastern and western Kenya. However, it should be noted that, the numbers given are estimations because it is difficult (or even impossible) to be sure that these additional categories consist of just one species (already listed or not) or more species. The medium trial of Embu had relatively higher species richness compared to the mediumterm trial of Kakamega and long-term trial of Nyabeda, and the highest number of species (37) was recorded in the Embu medium-term trial followed by Nyabeda (32) > Kakamega (27) (Data is available as Supplementary Tables). The macrofauna groups were dominated by Oligochaeta (earthworms), Isoptera (termites), Hymenoptera (ants), and Coleoptera (beetles), with these groups constituting over $80 \%$ of mean totals across the different trials (Table 3). In Embu medium-term trial, Hymenoptera were the most abundant of these faunal groups, constituting about $39 \%$ of the mean total followed by Isoptera (28\%), Coleoptera (12\%), and Oligochaeta (10\%) (Table 3). In Kakamega trial, Oligochaeta (64\%) was the most dominant of all the macrofauna groups followed by Isoptera (7\%) > Hymenoptera $(6 \%)>$ Coleoptera (5\%), whereas in Nyabeda, Isoptera was dominant (55\%) followed by Oligochaeta $(21 \%)$ $>$ Hymenoptera $>$ Coleoptera $(6 \%)$ in that order. In all the trials, however, the other macrofauna groups were observed in very low numbers, with each group constituting $\leq 5 \%$ (Table 3 ). Generally, macrofauna were more abundant in the eastern Kenya than in western Kenya sites, with the former recording a mean total between 875 and 1,386 numbers per $\mathrm{m}^{-2}$ compared to that between 565 and 784 numbers per $\mathrm{m}^{-2}$ in the latter (Table 3).

For mesofauna groups, 18 species classified into seven major groups were observed across the four trials, and the western Kenya sites (Nyabeda and Kakamega) had relatively higher mesofauna richness compared to the eastern Kenya (Embu) sites
(Data is available as a Supplementary Tables). Mesofauna was equally relatively more abundant in the western Kenya sites compared to the eastern Kenya site (Table 3). In the eastern Kenya (Embu) trial, mesofauna groups were dominated by Acarina, which constituted $>50 \%$ followed by Collembolla (16$17 \%$ ) and Enchytraeids (10-15\%), with each of the other groups constituting $<6 \%$ (Table 3). Western Kenya trials were also dominated by Acarina (40-59\%) and Collembolla (35-46\%) and the other groups each constituted $\leq 5 \%$ (Table 3 ).

\section{Soil Fauna Taxonomic Richness}

The combinations of tillage practice, organic residues and cropping system had significant effect on macrofauna taxonomic richness $(p<0.05)$ largely at the top $0-15 \mathrm{~cm}$ soil depth than at the lower $15-30 \mathrm{~cm}$ soil depth in most of the study sites (Figure 1). At $0-15 \mathrm{~cm}$ soil depth of the Embu medium-term trial, mean macrofauna taxonomic richness was significantly higher in both conservation agriculture under sole maize $(\mathrm{CASM}+\mathrm{CR})$ cropping and conservation agriculture under maize-bean intercrop $(\mathrm{CAMBi}+\mathrm{CR})$ treatments than in either conventional till minus crop residues under maize-bean intercrop (CTMBi-CR) or conservation agriculture under sole beans (CASB $+\mathrm{CR}$ ) (Figure 1A). At 15-30 cm, mean macrofauna taxonomic richness did not differ among the treatments $(p=$ 0.503) (Figure 1B). At the Kakamega, no significant differences were noted for macrofauna mean richness among the treatments at both $0-15$ and $15-30 \mathrm{~cm}$ soil depths (Figures 1C,D). At Nyabeda, macrofauna richness was significantly lower in conventional (typical farmer's practice without residues) till without inputs than in the other treatments (Figure 1E). At $15-30 \mathrm{~cm}$, mean macrofauna taxonomic richness did not differ among the treatments $(p=0.370)$ (Figure 1F).

In addition, no significant differences were noted for mesofauna mean richness among the treatments at both $0-15 \mathrm{~cm}$ and $15-30 \mathrm{~cm}$ soil depths in all study sites (Figure 2). As 
TABLE 3 | Mean total population and percent composition of macrofauna and mesofauna within each group across medium-term (MT) and long-term (LT) trials in Embu, Kakamega, and Nyabeda, Kenya.

\begin{tabular}{|c|c|c|c|c|c|c|}
\hline \multirow[b]{2}{*}{ Macrofauna group } & \multicolumn{2}{|c|}{ Embu-MT } & \multicolumn{2}{|c|}{ Kakamega-MT } & \multicolumn{2}{|c|}{ Nyabeda-LT } \\
\hline & Mean total & $\%$ of total & Mean total & $\%$ of total & Mean total & $\%$ of total \\
\hline Oligochaeta & 136 & 9.8 & 499 & 63.6 & 120 & 21.2 \\
\hline Isoptera & 381 & 27.5 & 58 & 7.4 & 312 & 55.2 \\
\hline Hymenoptera & 545 & 39.3 & 46 & 5.9 & 56 & 9.9 \\
\hline Coleoptera & 171 & 12.3 & 39 & 5.0 & 36 & 6.4 \\
\hline Diptera & 15 & 1.1 & 4 & 0.5 & 4 & 0.7 \\
\hline Lepidoptera & 33 & 2.4 & 16 & 2.0 & 4 & 0.7 \\
\hline Diplopoda & 24 & 1.7 & 38 & 4.8 & 1 & 0.2 \\
\hline Chilopoda & 34 & 2.4 & 39 & 5.0 & 7 & 1.2 \\
\hline Orthoptera & 21 & 1.5 & 4 & 0.5 & 3 & 0.5 \\
\hline Araneae & 11 & 0.8 & 20 & 2.5 & 17 & 3.1 \\
\hline Odonata & 3 & 0.2 & - & - & 4 & 0.7 \\
\hline Hemiptera & 4 & 0.3 & 22 & 2.8 & 1 & 0.2 \\
\hline Blattoidea & 5 & 0.4 & - & - & - & - \\
\hline Isopoda & 3 & 0.2 & - & - & - & - \\
\hline Total & 1,386 & 100 & 784 & 100 & 565 & 100 \\
\hline \multicolumn{7}{|l|}{ Mesofauna group } \\
\hline Acarina & 592 & 57.9 & 1,196 & 39.5 & 2,900 & 58.9 \\
\hline Arachnida & 3 & 0.2 & - & - & - & - \\
\hline Collembolla & 172 & 16.9 & 1,392 & 46.0 & 1,741 & 35.3 \\
\hline Diplura & 50 & 4.9 & 155 & 5.1 & 32 & 0.6 \\
\hline Enchytraeidae & 150 & 14.7 & 14 & 0.5 & 11 & 0.2 \\
\hline Protura & 55 & 5.4 & - & - & - & - \\
\hline Symphyla & - & - & 268 & 8.9 & 243 & 4.9 \\
\hline Total & 1,022 & 100 & 3,025 & 100 & 4,927 & 100 \\
\hline
\end{tabular}

expected, soil fauna richness reduced with depth where these were nearly $\leq 50 \%$ that of top soil for each of the treatments.

\section{Soil Fauna Abundance}

Across all sites, and in both $(0-15$ and $15-30 \mathrm{~cm})$ soil depths, no significant effect of tillage, cropping and organic inputs on soil macrofauna abundance were observed (Figure 3). Equally no significant treatment effects on soil mesofauna abundance were observed in Embu medium-term (Figures 4A,B) and Nyabeda long-term trials for both soil depths (Figures 4E,F). Although a similar observation was made on mesofauna abundance at the $15-30 \mathrm{~cm}$ soil depth of Kakamega trial (Figure 4D), at $0-15 \mathrm{~cm}$ soil depth, maize-bean intercrop system under conservation agriculture $(\mathrm{CAMBi}+\mathrm{CR})$ had significantly higher mesofauna abundance than the convention till with similar management (CTMBi+CR) practices or conventional till (farmers practice) without any inputs (Figure 4C).

\section{Soil Fauna Group Abundance Across Treatments}

Faunal abundance were analyzed and assessment made depthwise across treatments for the various groups.

\section{Macrofauna}

In the long-term trial, tillage, residue application and cropping system affected only a few of the macrofauna groups such as
Oligochaeta, Chilopoda, and Araneae, but only at the top soil depth. This is unlike medium-term trials where significant effects were noted in either depths (Table 4).

At $0-15 \mathrm{~cm}$ soil depth, in the Embu medium-term trial, Oligochaete, and Araneae were significantly more abundant in both conservation agriculture, maize-bean intercropping system with residues $(\mathrm{CAMB}+\mathrm{CR})$ and conservation agriculture, sole maize with residues $(\mathrm{CASM}+\mathrm{CR})$ treatments than zero till, sole beans with residues $(\mathrm{CASB}+\mathrm{CR})$ and conventional till, maize bean system without residues treatments (CTMBCR) (Table 4). Chilopoda, however, were significantly more abundant in CASM+CR than in the other treatments. The other macrofauna groups did not differ among the treatments, and at $15-30 \mathrm{~cm}$, all the macrofauna groups did not differ among the treatments as well.

In Kakamega, management practices affected only Oligochaeta and Chilopoda groups but only at $0-15$ and $15-$ $30 \mathrm{~cm}$ soil depths, respectively. At $0-15 \mathrm{~cm}$ depth, maize-bean intercrop system under conservation agriculture with residue applied $(\mathrm{CAMBi}+\mathrm{CR})$ had significantly higher Oligochaete abundance than the convention till with similar management $(\mathrm{CTMBi}+\mathrm{CR})$ practices or conventional till (farmers practice: FP) without any inputs. At $0-15 \mathrm{~cm}$, the predacious Chilopod group, was on the other hand, significantly higher in famers practice (FP-conventional till without any inputs) than in the other treatments. 
A

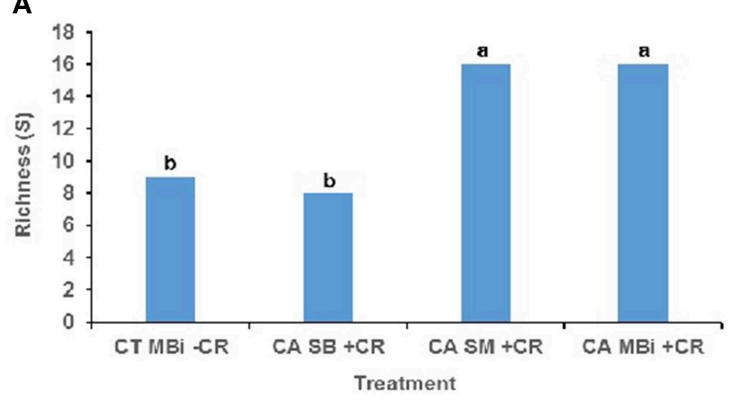

C

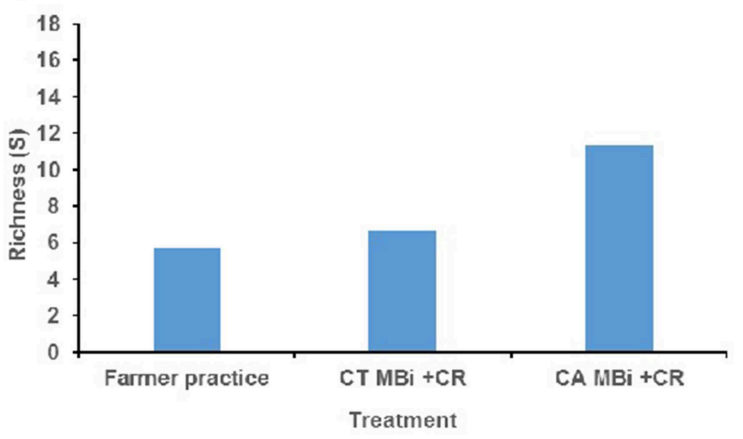

E

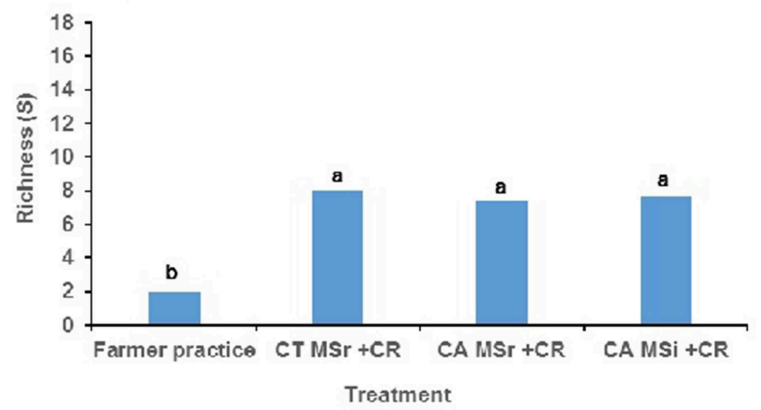

B

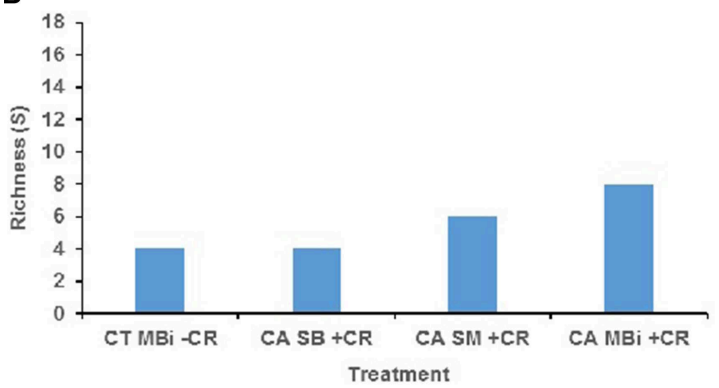

D

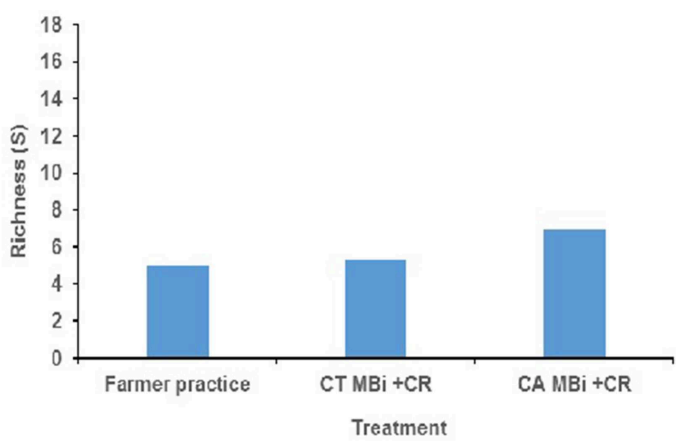

$\mathbf{F}$

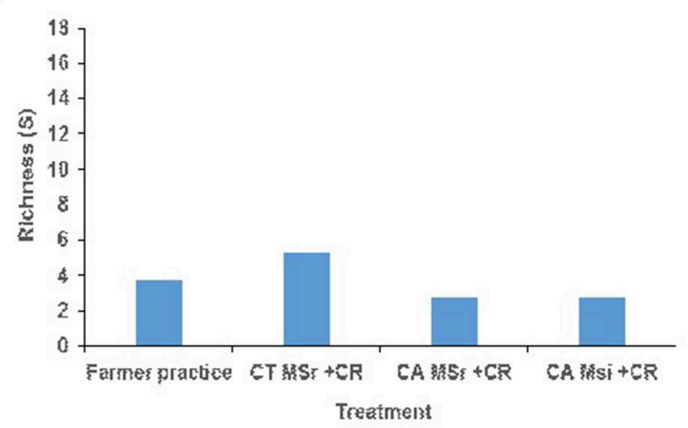

FIGURE 1 | Soil macrofauna diversity (richness) across trials of Embu, Kakamega, and Nyabeda. MT, Medium-term; LT, Long-term; CT, Conventional till; CA, Conservation agriculture (Zero till); SM, Sole maize; SB, Sole beans; MBi, Maize bean intercrop; MSi, Maize-soybean intercrop; MSr, Maize-soybean rotation; CR, Crop residue. (A) Embu MT (0-15 cm, p = 0.027); (B) Embu MT (15-30 cm, p = 0.503); (C) Kakamega MT (0-15 cm, p = 0.329); (D) Kakamega MT (15-30 cm, $p=0.414)$; (E) Nyabeda $L T\left(0-15 \mathrm{~cm}, p=0.029^{*}\right) ;(\mathbf{F})$ Nyabeda $L T(15-30 \mathrm{~cm}, p=0.370)$. Bars with different lower case letters are statistically significantly different at $p<0.05$.

At $0-15 \mathrm{~cm}$ soil depth of Nyabeda, cropping system and residue addition seem to be the influencing factors for Hymenoptera abundance as this group was significantly higher under maize-soybean rotation system for both conventional $(\mathrm{CTMSr}+\mathrm{CR})$ and conservation agriculture systems with crop residue applied (CAMSr+CR) than in the conventional till under continuous maize without inputs (FP) and conservation agriculture under maize soybean intercrop but with crop residues (CAMSr+CR). No significant treatment effects were observed for the other macrofauna groups at this top soil depth and for all the macrofauna groups at $15-30 \mathrm{~cm}$ soil depth.

\section{Mesofauna}

In the medium-term trial of Embu, and in both soil depths, all the mesofauna groups did not differ among the treatments indicating lack of significant influence of tillage, organic residue application and crop management (Table 5). However, significant effect of tillage on mesofauna abundance were noted at top $0-15 \mathrm{~cm}$ soil depths for both Kakamega and Nyabeda trials. At Kakamega, Collembolan group was significantly higher in the conservation agriculture practices than in the conventional till practices, and the same pattern was observed for Symphyla group in the Nyabeda trial. As expected, mesofauna groups were less abundant in the lower soil depths compared to the upper depths.

\section{Management Practices and Effect on Soil Chemical Properties}

Soil management practices had significant effects on soil chemical properties (Table 6). In Embu site, soil TOC was significantly lower in conservation tillage under sole maize (CASM+CR) than in all the other treatments. Total organic $\mathrm{N}$, on the other hand, was significantly higher in conventional tillage under 
A

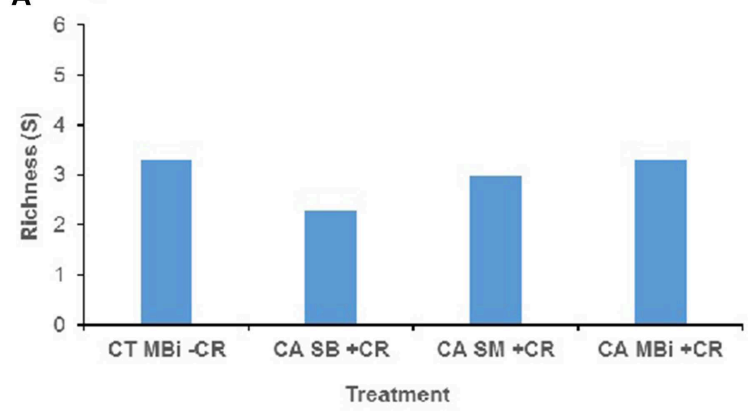

C

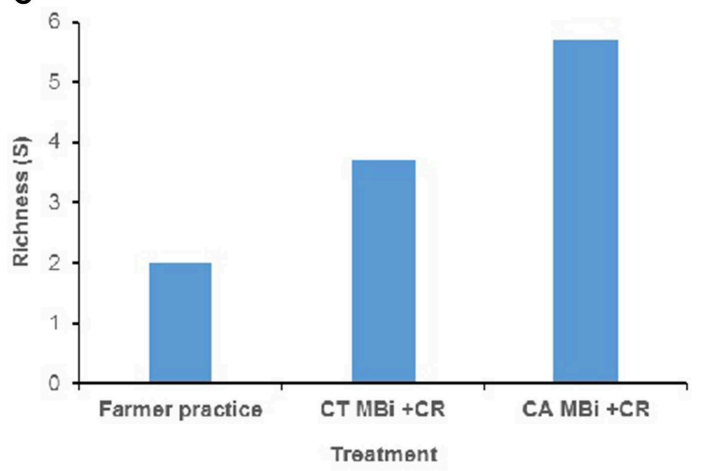

E

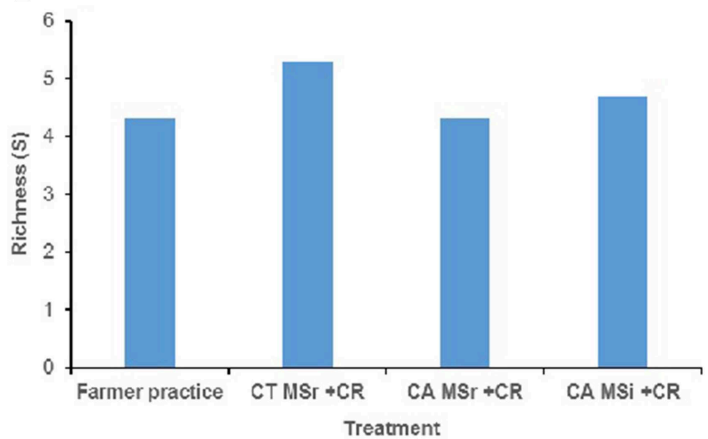

B

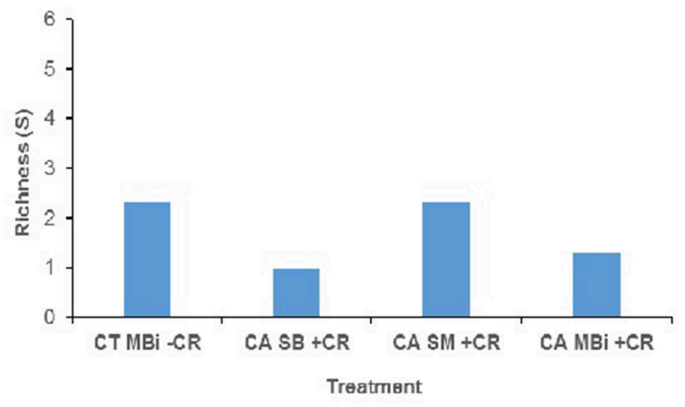

D 6 -

$5-$

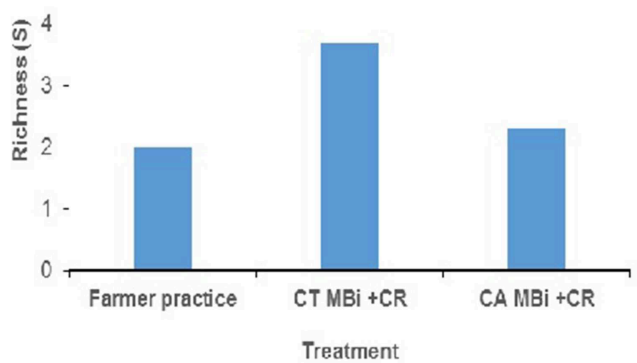

$\mathbf{F}$

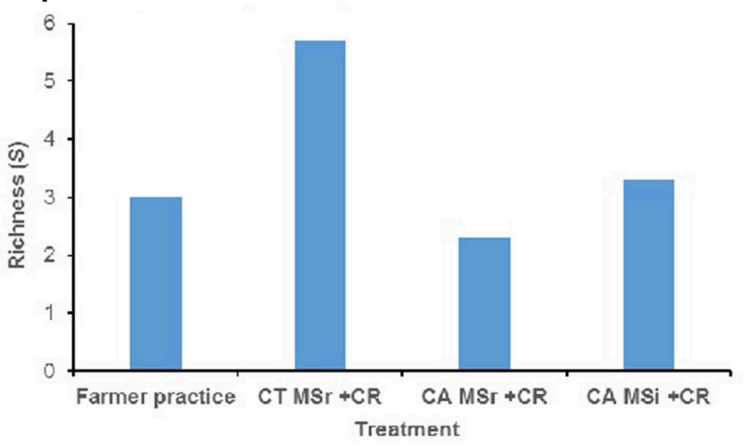

FIGURE 2 | Soil mesofauna diversity (richness) across trials of Embu, Kakamega, and Nyabeda. MT, Medium-term; LT, Long-term; CT, Conventional till; CA, Conservation agriculture (Zero till); SM, Sole maize; SB, Sole beans; MBi, Maize bean intercrop; MSi, Maize-soybean intercrop; MSr, Maize-soybean rotation; CR, Crop residue. (A) Embu MT (0-15 cm, p = 0.864); (B) Embu MT (15-30 cm, p = 0.515); (C) Kakamega MT (0-15 cm, p=0.058); (D) Kakamega MT (15-30 cm, p = 0.502); (E) Nyabeda LT (0-15 cm, $p=0.405)$; (F) Nyabeda LT $(15-30 \mathrm{~cm}, p=0.125)$.

maize-bean intercrop without crop residues (CTMBi-CR) than in the conservation tillage practices under sole maize and maize-bean intercrop (Table 6). It however, did not differ from conservation tillage under sole beans. In Kakamega site, soil pH was significantly higher in conventional tillage under maize-bean intercrop with crop residues than in conservation tillage under intercrop $(\mathrm{CAMBi}+\mathrm{CR})$ and farmer practice $(\mathrm{FP})$, and a trend similar to that of soil $\mathrm{pH}$ was observed for $\mathrm{Ca}$ and $\mathrm{Mg}$ (Table 6). Tillage influenced TOC and P contents, and were significantly higher in conservation tillage under intercrop (CAMBi+CR) than in the conventional tillage under intercrop (CA $\mathrm{MBi}+\mathrm{CR}$ ) and farmer practice (FP). Although TON was significantly higher in $\mathrm{CAMBi}+\mathrm{CR}$ than $\mathrm{FP}$, it did not differ from CTMBi+CR
(Table 6). At Nyabeda, treatment effect was observed only for soil $\mathrm{pH}, \mathrm{Ca}$, and $\mathrm{Mg}$. Soil $\mathrm{pH}$ was higher in CTMSr+CR than either $\mathrm{CAMSi}+\mathrm{CR}$ or FP although it did not differ from CAMSr+CR. Calcium content was highest in $\mathrm{CAMSr}+\mathrm{CR}>\mathrm{CTMSr}+\mathrm{CR}>$ $\mathrm{FP}$, but lowest in CAMSi +CR. Magnesium content on the other hand was highest in $\mathrm{CTMSr}+\mathrm{CR}>\mathrm{CAMSr}+\mathrm{CR}>\mathrm{FP}$, but again lowest in CAMSi+CR (Table 6).

\section{Correlation Between Soil Fauna and Soil Chemical Properties}

Over $60 \%$ of the macrofauna, and over $70 \%$ of mesofauna showed significant correlation with soil parameters (Table 7). Oligochaeta, Diplopoda, and Hemiptera significantly positively 
A

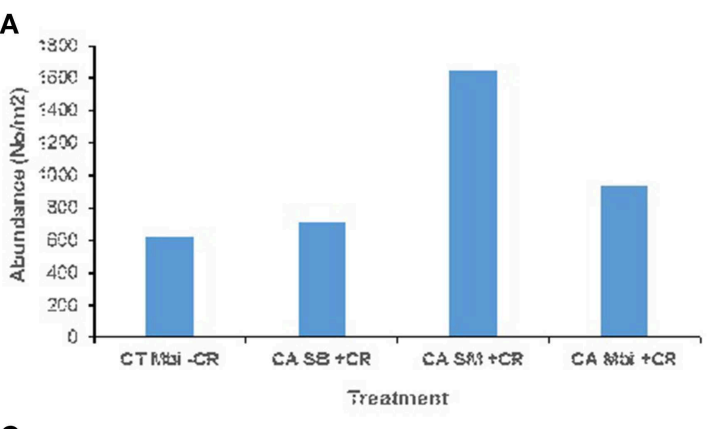

C

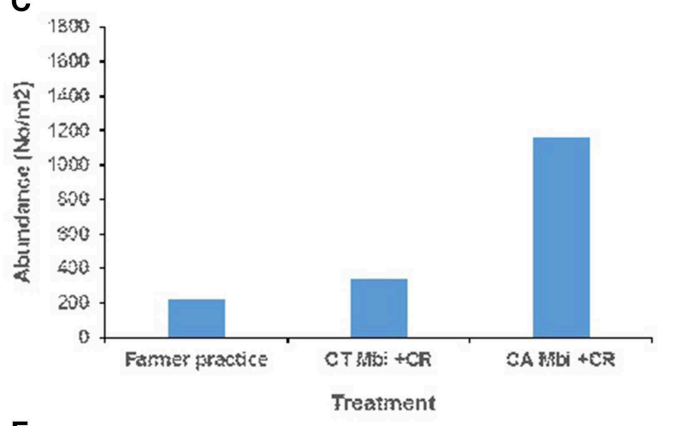

E

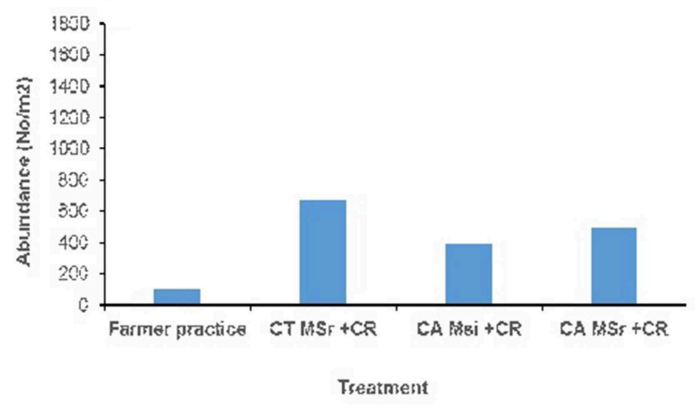

B

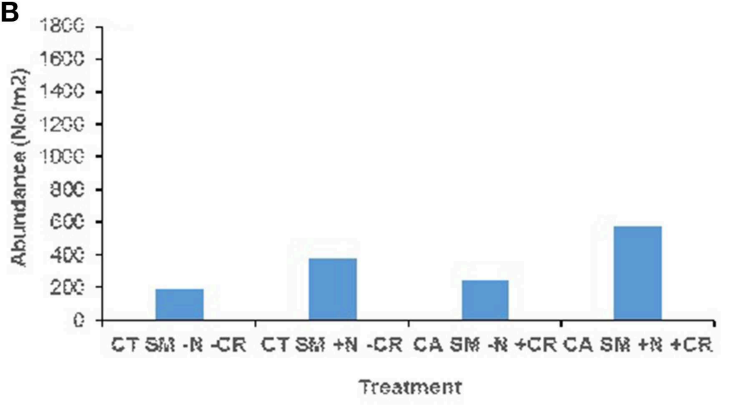

D
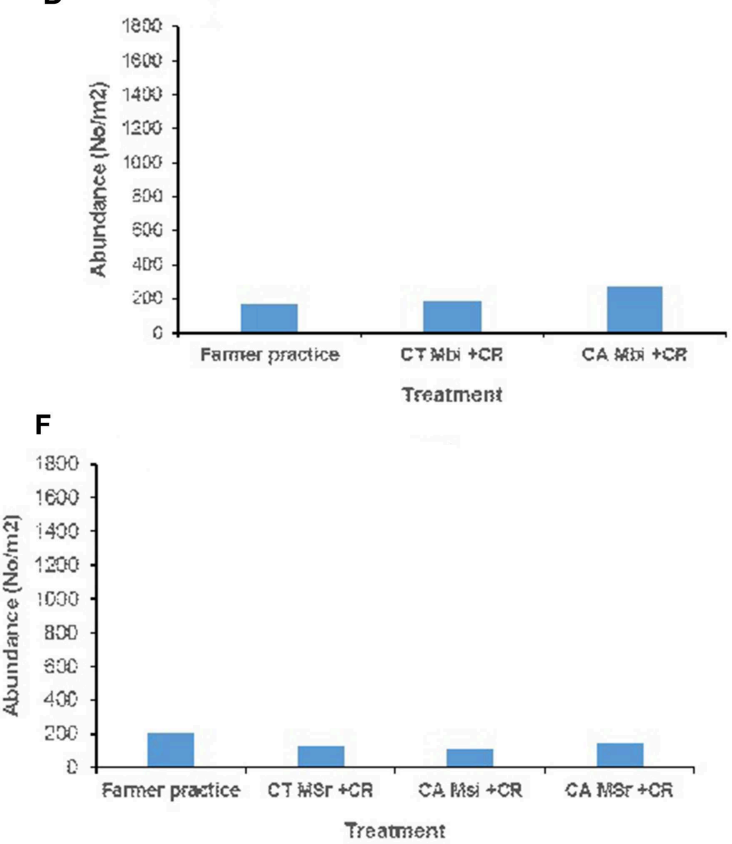

FIGURE 3 | Soil macrofauna abundance across trials of Embu, Kakamega, and Nyabeda. MT, Medium-term; LT, Long-term; CT, Conventional till; CA, Conservation agriculture (Zero till); SM, Sole maize; SB, Sole beans; MBi, Maize bean intercrop; MSi, Maize-soybean intercrop; MSr, Maize-soybean rotation; CR, Crop residue. (A) Embu MT (0-15 cm, p = 0.316); (B) Embu ST (15-30 cm, p = 0.075); (C) Kakamega MT (0-15 cm, p = 0.128); (D) Kakamega MT (15-30 cm, $p=0.383) ;$ (E) Nyabeda LT (0-15 cm, $p=0.285) ;(\mathbf{F})$ Nyabeda LT $(15-30 \mathrm{~cm}, \mathrm{p}=0.843)$.

correlated with soil organic matter (TOC, TON) and P, whereas Hymenoptera, Coleoptera and Blattodea positively correlated with nearly all the exchangeable bases ( $\mathrm{Na}, \mathrm{K}, \mathrm{Ca}$, and $\mathrm{Mg}$ ). Diptera, Lepidoptera, and Odonata on the other hand significantly correlated with all exchangeable bases measured (except $\mathrm{K}$ and $\mathrm{Mg}$ ). Whereas, Orthoptera positively correlated with $\mathrm{Mg}$, and Isopoda positively with $\mathrm{K}$, Chilopoda negatively correlated with soil $\mathrm{pH}$ (Table 7). Mesofauna groups on the other hand showed significant correlations with exchangeable bases ( $\mathrm{Na}, \mathrm{K}, \mathrm{Ca}$, and $\mathrm{Mg}$ ) only. Whereas, Enchytraeid and Protura positively correlated with all the exchangeable bases and Arachnida with Mg, Acarina, Collembolla, and Symphila negatively correlated with all the bases.

\section{DISCUSSION}

The total number of macrofauna taxa of between 25 and 37 recorded in our study sites conforms with the range of 35-38 taxa recorded by Ayuke (2000) and Ayuke et al. (2009) across arable fields within western and eastern Kenya, respectively. However, these taxa were much lower than 75 taxa recorded by Karanja et al. (2009) across arable sites of a different ecozone, the Coastal region of Kenya. Mesofauna total taxa were, however, three times higher than that recorded under biomass transfer agroforestry technology at Maseno, Western Kenya (Ayuke, 2000).

Results of this study have demonstrated the benefits of conservation agriculture in enhancing soil fauna richness and abundance. Higher macrofauna taxonomic richness and abundance of mesofauna in CA treatments than in CT without residue application are related to an improved microclimate and access to food in the CA system. Disturbances caused by tillage operations and residue removal (CT) are known to negatively affect sensitive fauna (Ayuke et al., 2011a,b), except for the predating and foraging groups like Hymenoptera (ants), Chilopoda (centipedes) and some species of Isoptera (termites) e.g., Microtermes sp. Earthworm species, among them, the 

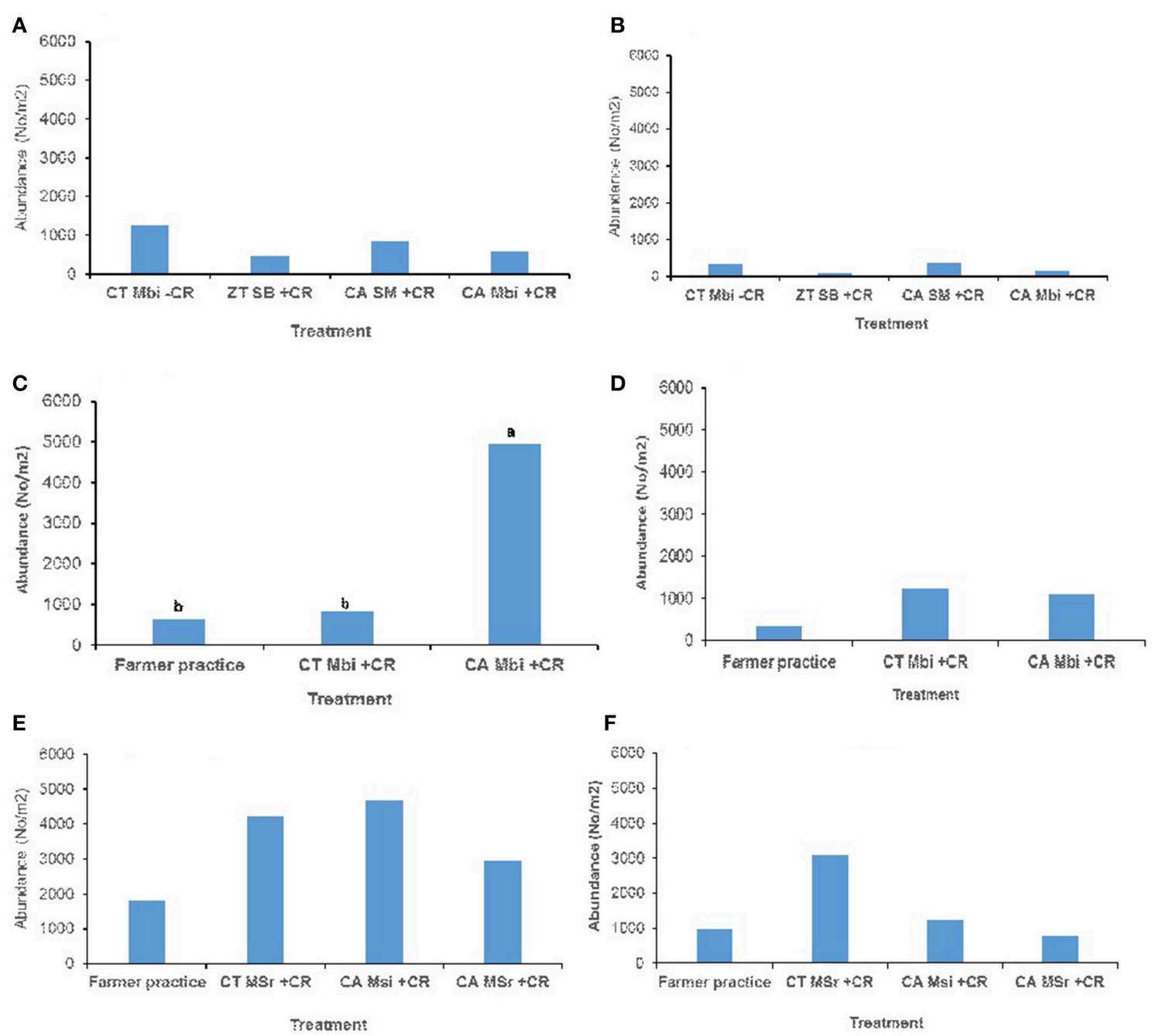

FIGURE 4 | Soil mesofauna abundance across trials of Embu, Kakamega, and Nyabeda. MT, Medium-term; LT, Long-term; CT, Conventional till; CA, Conservation agriculture (Zero till); SM, Sole maize; SB, Sole beans; MBi, Maize bean intercrop; MSi, Maize-soybean intercrop; MSr, Maize-soybean rotation; CR, Crop residue. (A) Embu MT (0-15 cm, p = 0.664); (B) Embu MT (15-30 cm, $p=0.233)$; (C) Kakamega MT (0-15 cm, $\left.p=0.036^{*}\right)$; (D) Kakamega MT (15-30 cm, $\left.p=0.347\right)$; (E) Nyabeda LT (0-15 cm, $p=0.425)$; (F) Nyabeda $L T(15-30 \mathrm{~cm}, \mathrm{p}=0.256)$. Bars with different lower case letters are statistically significantly different at $p<0.05$.

Dichogaster sp. are also sensitive to disturbance (Ayuke et al., $2011 \mathrm{a}, \mathrm{b})$, and so were lacking under conventional till as opposed to conservation agriculture system.

Microclimate modification, food resource availability, and land Management practices (e.g., tillage, organic resource use, crop rotation, and application of agrochemicals such as pesticides, herbicides, and inorganic fertilizers) are known to either positively or negatively influence the diversity and abundance of soil fauna communities (Dangerfield, 1993; Beare et al., 1997; Nhamo, 2007; Gianessi, 2010; Isenring, 2010). Tillage influences soil fauna in several ways: the mechanical and physical disturbance due to tillage can cause habitat destruction for some of the macrofauna groups. When vegetation are removed, the resultant change in habitat structure, the reduced range and abundance of food resources and the extreme climate at the soil surface, most likely combine to create harsh environment that may be intolerable to most soil fauna groups among them earthworms. Consequently, the population of these soil fauna groups could be suppressed, possibly explaining why some species of earthworms, springtails (Collembolla) and Symphyla were absent from the conventional till systems, hence the lower diversity and abundances observed. However, predacious fauna groups such as ants (Hymenoptera) were favored by tillage as this exposed their likely prey among them termites, on to the soil surface hence abundant food.

Conservation agriculture favored those fauna groups e.g., earthworms (Oligochaeta) and predacious spiders (Araneae) that are sensitive to disturbance caused by tillage. Many known Araneae (spider) species live on the soil surface or in soil crevices, invade the natural pore system of soils or are in some way closely associated with the soil systems. Higher Araneae recorded under CA practices could be attributed to less disturbance 
TABLE 4 | Mean abundance of soil macrofauna groups across treatments in medium-term and long term trials of Embu, Kakamega, and Nyabeda, Kenya.

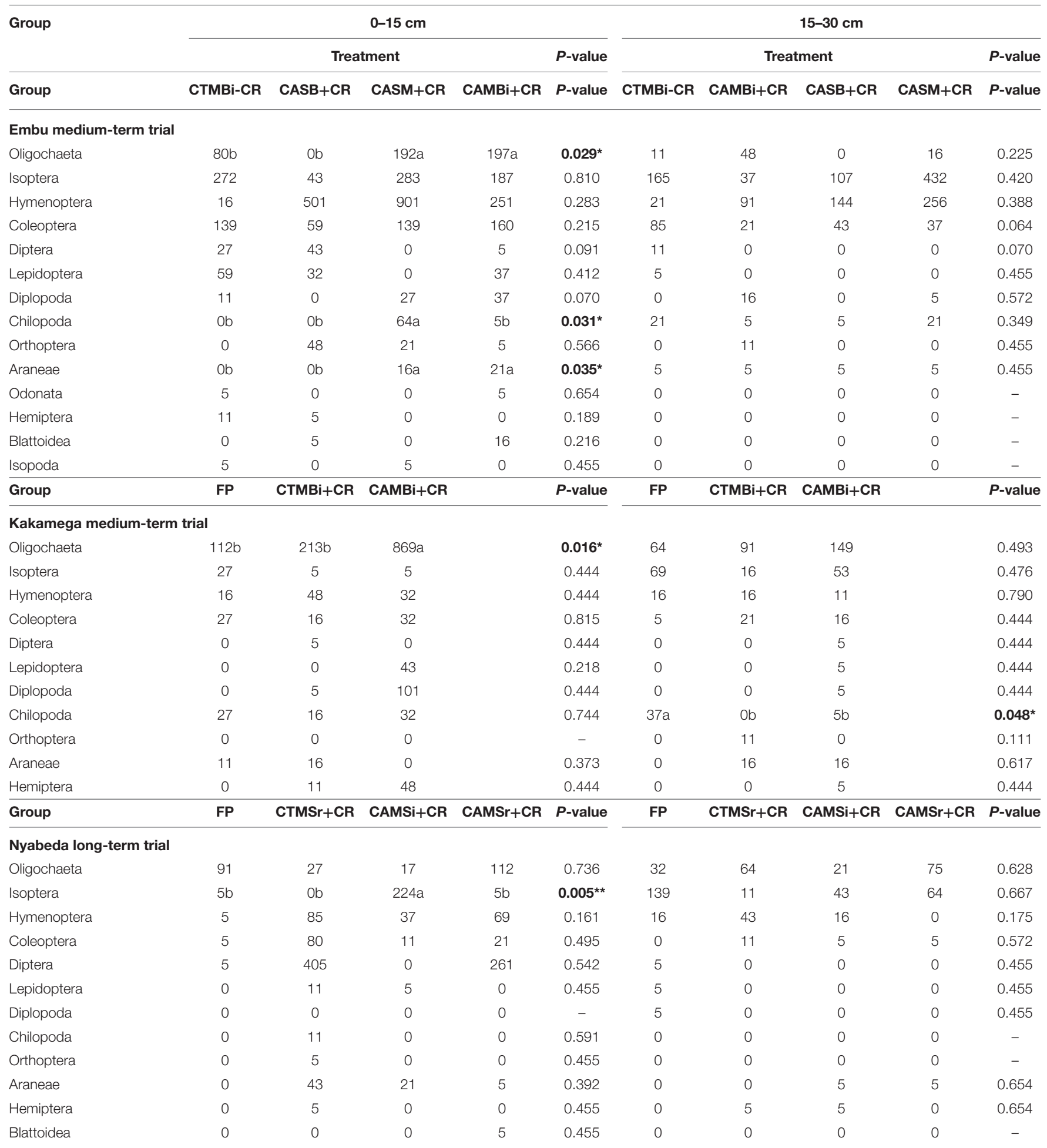

Means followed by the same lowercase letters across rows are not significantly different at $p<0.05$. Significant $p$-values are indicated in bold. For some of the groups with zeros at lower depths, ANOVA did not calculate the p-value. For treatment abbreviations (see Table 2). *Significant; **Highly significant; ***Very highly significant.

that might have affected the populations of their likely prey. It has been shown that, reduced- or no-tillage agriculture is beneficial for soil conservation in that, soil-surface accumulation of crop residues as a result of minimal soil disturbance protects soil from water and wind erosion (Stinner and House, 1990). Unlike in conventional tillage, litter and soil organic matter 
TABLE 5 | Mean abundance of soil mesofauna groups across treatments in long- and short-term trials of Embu, Nyabeda, and Kakamega.

\begin{tabular}{|c|c|c|c|c|c|c|c|c|c|c|}
\hline \multirow[b]{2}{*}{ Group } & \multicolumn{3}{|c|}{$\begin{array}{c}0-15 \mathrm{~cm} \\
\text { Treatment }\end{array}$} & \multicolumn{7}{|c|}{$\begin{array}{l}15-30 \mathrm{~cm} \\
\text { Treatment }\end{array}$} \\
\hline & CTMBi-CR & $\mathrm{CASB}+\mathrm{CR}$ & CASM+CR & CAMBi+CR & $P$-value & CTMBi-CR & $\mathrm{CASB}+\mathrm{CR}$ & CASM+CR & $\mathrm{CAMBi}+\mathrm{CR}$ & $P$-value \\
\hline \multicolumn{11}{|c|}{ Embu medium-term trial } \\
\hline Acarina & 1,100 & 233 & 533 & 233 & 0.415 & 33 & 33 & 133 & 67 & 0.142 \\
\hline Arachnida & 0 & 167 & 0 & 167 & 0.654 & 0 & 0 & 0 & 0 & - \\
\hline Diplura & 67 & 33 & 33 & 0 & 0.714 & 0 & 0 & 33 & 33 & 0.654 \\
\hline Enchytraeidae & 0 & 67 & 100 & 167 & 0.136 & 133 & 67 & 33 & 33 & 0.285 \\
\hline Protura & 33 & 33 & 0 & 67 & 0.572 & 100 & 0 & 33 & 0 & 0.285 \\
\hline Group & FP & $\mathrm{CTMBi}+\mathrm{CR}$ & $\mathrm{CAMBi}+\mathrm{CR}$ & & $P$-value & FP & $\mathrm{CTMBi}+\mathrm{CR}$ & $\mathrm{CAMBI}+\mathrm{CR}$ & & $P$-value \\
\hline \multicolumn{11}{|c|}{ Kakamega medium-term trial } \\
\hline Enchytraeidae & 42 & 0 & 0 & & 0.444 & 0 & 0 & 0 & & - \\
\hline Symphyla & 0 & 211 & 169 & & 0.132 & 127 & 295 & 0 & & 0.273 \\
\hline Group & FP & CTMSr+CR & CAMSi+CR & $\mathrm{CAMSr}+\mathrm{CR}$ & $P$-value & FP & CTMSr+CR & CAMSi+CR & $\mathrm{CAMSr}+\mathrm{CR}$ & $P$-value \\
\hline \multicolumn{11}{|c|}{ Nyabeda long-term trial } \\
\hline Acarina & 1,350 & 2,110 & 2,363 & 2,363 & 0.538 & 464 & 1,772 & 676 & 506 & 0.199 \\
\hline Collembola & 338 & 2,110 & 2,012 & 295 & 0.224 & 380 & 1,224 & 338 & 253 & 0.441 \\
\hline Diplura & 0 & 0 & 0 & 0 & - & 84 & 42 & 0 & 0 & 0.613 \\
\hline Enchytraeidae & 42 & 0 & 0 & 0 & 0.455 & 0 & 0 & 0 & 0 & - \\
\hline Symphyla & $84 b$ & ob & $295 a$ & $295 a$ & $0.025^{\star}$ & 42 & 42 & 211 & 0 & 0.150 \\
\hline
\end{tabular}

Means followed by the same lowercase letters across rows are not significantly different at $p<0.05$. Significant $p$ values are indicated in bold. For treatment abbreviations (see Table 2). *Significant; **Highly significant; ${ }^{* \star *}$ Very highly significant.

(and also nutrients) tend to concentrate near the soil surface of conservation-tillage systems, and these condition are likely to favor soil fauna within the CA. Although crop or organic residues get incorporated into the soil, albeit slowly, through invertebrate activity (Ayuke et al., 2009; Kihara et al., 2015), the litter layer is a very important factor in ameliorating soil temperature and water content of soil, thus providing a more stable environment for soil- and litter-dwelling invertebrates. This may explain the expected higher macrofauna richness and mesofauna abundance observed in top-soils than sub-soils.

The important role of organic amendments in influencing presence and abundance of specific faunal groups have been discussed (Ayuke, 2000) and their role explains why, P. annulatus earthworm species that thrive best under high organic matter environments were only recorded under sole maize and maizebean CA systems where crop residues were retained, and detritus groups such as Collembolla and Symplyla were few under conventional till without residues. Equally no $P$. annulatus worms were recorded under CA with sole bean system where highly transient bean residues had been applied. Indeed, we observed during fauna sampling (eight weeks after cropping), that none of the trash remained at the soil surface, probably due to fast disappearance and rapid decomposition of bean trash. Soil fauna were deprived of food resources as a result hence were low or absent in such systems. Oligochaeta, Araneae, and Chilopoda were favored with long-term addition of organic residues while Isoptera were favored in the medium-term. In our study sites, earthworms were dominated by the epigeics (those living on top soil layers but forage primarily on plant residuese.g., Dichogaster sp. and $P$. annulatus) and the endogeics (those living and feeding in the soil but foraging on soil organic matter). The main source of organic matter as food for earthworms include litter from aboveground plant parts, but dead roots and rhizodeposition can also be important food sources (Curry, 2004). Because earthworms are often food limited, their population can increase following organic amendments (Lowe and Butt, 2002; Ayuke et al., 2011b). Higher numbers of Oligochaeta (earthworms) in treatments with organic residues could be attributed to abundant food resources due to crop residues. Importance of soil organic matter as food and energy sources is reinforced by the positive correlations observed between TOC and TON as well as P with some of the macrofauna groups such as Oligochaeta, Diplopoda, and Hemiptera. Exchangeable bases $(\mathrm{Na}, \mathrm{K}, \mathrm{Ca}$, and $\mathrm{Mg}$ ) are equally important for some of the fauna groups where they are used in the formation of body parts such as the exoskeletons.

In natural ecosystems, spiders constitute the main invertebrate predatory group hence play an important ecological function in pest control. Araneae being mostly polyphagous predators, can significantly affect the population dynamics of many 
TABLE 6 | Soil chemical characteristics (0-30 cm soil depth) across treatments of Embu, Nyabeda, and Kakamega.

\begin{tabular}{|c|c|c|c|c|c|c|c|c|c|}
\hline Site & Treatment & Soil pH & TOC & TON & $\mathbf{P}$ & $\mathrm{Na}$ & $\mathbf{K}$ & $\mathrm{Ca}$ & Mg \\
\hline \multirow[t]{5}{*}{ Embu-MT } & CT MBi -CR & 4.75 & $2.43 a$ & $0.23 a$ & 15.87 & 0.27 & 0.58 & 2.23 & 4.30 \\
\hline & CA SB +CR & 4.83 & $2.45 a$ & $0.22 \mathrm{ab}$ & 14.20 & 0.24 & 0.67 & 2.27 & 5.25 \\
\hline & CA SM +CR & 4.56 & $2.20 b$ & $0.20 b$ & 16.67 & 0.16 & 0.41 & 1.77 & 5.49 \\
\hline & $\mathrm{CA} \mathrm{MBi}+\mathrm{CR}$ & 4.54 & $2.47 a$ & $0.18 b$ & 16.67 & 0.17 & 0.50 & 1.83 & 5.46 \\
\hline & $P$-value & 0.428 & $0.040^{\star}$ & $0.016^{\star}$ & 0.946 & 0.491 & 0.377 & 0.515 & 0.362 \\
\hline \multirow[t]{4}{*}{ Kakamega-MT } & FP & $4.63 b$ & $3.26 b$ & $0.26 b$ & $36.10 b$ & 0.02 & 0.07 & $0.68 b$ & $0.08 b$ \\
\hline & $\mathrm{CT} \mathrm{MBi}+\mathrm{CR}$ & $5.22 \mathrm{a}$ & $3.57 b$ & $0.29 a b$ & $4.74 b$ & 0.02 & 0.16 & $1.34 \mathrm{a}$ & $0.18 a$ \\
\hline & $\mathrm{CA} \mathrm{MBi}+\mathrm{CR}$ & $4.59 b$ & $4.07 a$ & $0.32 a$ & 93.30a & 0.02 & 0.11 & $0.59 b$ & $0.08 b$ \\
\hline & $P$-value & $0.023^{\star}$ & $0.012^{\star}$ & $0.020^{\star}$ & $0.011^{*}$ & 0.791 & 0.162 & $0.018^{\star}$ & $0.014^{\star}$ \\
\hline \multirow[t]{5}{*}{ Nyabeda-LT } & FP & $4.95 b$ & 2.39 & 0.18 & 36.57 & 0.03 & 0.09 & $0.73 c$ & $0.10 c$ \\
\hline & CT MSr +CR & $5.39 a$ & 2.36 & 0.18 & 30.10 & 0.03 & 0.05 & $0.85 b$ & $0.20 \mathrm{a}$ \\
\hline & $\mathrm{CA} \mathrm{MSr}+\mathrm{CR}$ & $5.18 \mathrm{ab}$ & 2.40 & 0.19 & 27.07 & 0.02 & 0.11 & $0.93 a$ & $0.14 b$ \\
\hline & $\mathrm{CA} M S i+C R$ & $4.67 b$ & 2.35 & 0.18 & 30.69 & 0.03 & 0.07 & $0.57 d$ & $0.08 d$ \\
\hline & $P$-value & $0.011^{*}$ & 0.954 & 0.856 & 0.181 & 0.735 & 0.114 & $0.004^{\star \star}$ & $<0.001^{* * *}$ \\
\hline
\end{tabular}

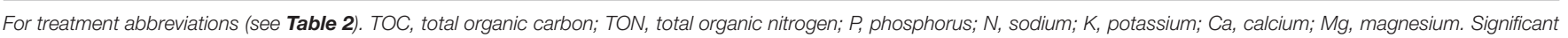
p-values are in bold. *Significant; **Highly significant; ${ }^{* \star *}$ Very highly significant.

TABLE 7 | Pearson correlation matrix of soil fauna and soil parameters.

\begin{tabular}{|c|c|c|c|c|c|c|c|c|}
\hline Fauna & jil pH & TOC & TON & $\mathbf{P}$ & $\mathrm{Na}$ & K & $\mathrm{Ca}$ & 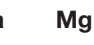 \\
\hline \multicolumn{9}{|l|}{ lacrofauna } \\
\hline igochaeta & -0.20 & $0.69^{\star \star \star}$ & $0.62^{\star \star \star}$ & $0.66^{\star \star \star}$ & -0.23 & $3-0.15$ & -0.28 & $3-0$. \\
\hline & & -0.24 & -0.30 & -0.07 & 0.11 & -0.01 & & \\
\hline . & -0.23 & -0.22 & -0.26 & -0.19 & $0.58^{\star \star \star}$ & * $0.39^{*}$ & $0.50^{* *}$ & 0.5 \\
\hline leopte & -0 & -0.25 & -0.05 & -0.10 & $0.60^{\star \star *}$ & ${ }^{*} 0.56^{\star \star \star}$ & $0.57^{\star \star \star *}$ & 0.5 \\
\hline & & -0.19 & & -0.12 & $0.41^{*}$ & 0.26 & $12^{*}$ & 31 \\
\hline pic & & & & 0.24 & 0.4 & 30 & & 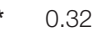 \\
\hline & -0 & 39* & $8^{*}$ & 1* & 04 & & & 0 \\
\hline & & & & & & & & ( \\
\hline th & & -0.22 & -0.13 & -0.13 & & & 20 & 0.4 \\
\hline & & 0.09 & -0.07 & 26 & 0.18 & $3-0.05$ & 23 & $3-0.1$ \\
\hline & -0 & -0.11 & 0.00 & -0.08 & & 32 & $0.38^{*}$ & 0 \\
\hline em & -0.13 & $0.44^{*}$ & $0.39^{*}$ & $0.45^{\star *}$ & -0.13 & $3-0.04$ & -0.18 & $3-0$. \\
\hline & & -0.19 & -0.11 & -0.22 & $0.44^{\star}$ & & 34 & 0.40 \\
\hline & & -0.11 & -0.05 & -0 & 22 & 0.6 & 28 & 0.2 \\
\hline \multicolumn{9}{|l|}{ Mesofaun } \\
\hline & & & -0 & 0.12 & & -0. & & \\
\hline acl & -0.07 & -0.19 & -0.05 & -0.12 & 0.25 & 0.16 & 0.23 & 0.42 \\
\hline & & 0.21 & & 0.34 & $-0.40^{*}$ & * $-0.37^{*}$ & $-0.41^{*}$ & -0.4 \\
\hline ent & & & & -0.01 & & -0.15 & -0.07 & -0 . \\
\hline nchytraeidae & -0.20 & -0.32 & -0.14 & -0.31 & $0.73^{\star * *}$ & $0.48^{\star *}$ & $0.71^{\star \star \star}$ & $0.72^{*}$ \\
\hline & & 0.23 & & 0.1 & $0.68^{\star \star \star}$ & ${ }^{*} 0.61^{\star \star *}$ & 0.65 & $0.55^{\prime}$ \\
\hline mprigia & .00 & 0.18 & 0.09 & 0.19 & $-0.49^{\star *}$ & ${ }^{\star}-0.47^{\star *}$ & $-0.50^{\star *}$ & -0.53 \\
\hline
\end{tabular}

For abbreviations (see Table 6). Significant p-values are in bold. *Significant; **Highly significant; ${ }^{\star \star \star}$ Very highly significant.

phytophagous and saprophagous invertebrates (Ekschmitt et al., 1997; Ziesche and Roth, 2008). In this study, CA most likely provided a conducive and prey-rich environment for Araneae. Chilopods (Centipedes) are among the oldest extant terrestrial arthropods and are an ecologically important group of soil and leaf litter predators (Undheim and King, 2011). In our study, higher Chilopod numbers was observed where maize stover residues had been applied in medium and long-term. It is possible that maize stover residues, apart from providing a moist conducive environment, might have favored availability of prey for Chilopods. Isoptera (termites) on the other hand, were favored by medium-term addition of organic residues and were therefore more abundant under CA than under CT without residues. Most of the isopteran species sampled in our study sites were all group II trophic members that are fungal growers, and typical feeders of wood, litter and grass. These species build subterranean nests and are sensitive to tillage disturbances (Ayuke et al., 2011b). Being foragers of wood, litter and grass, they were likely favored by addition of crop residues, and to avoid disturbance, they moved to deeper soil depths hence the significant differences observed at $15-30 \mathrm{~cm}$ soil depth.

Applications of plant residues have been shown to increase the population of earthworms (Ayuke et al., 2003; Fonte et al., 2009). Although other studies have demonstrated that short-term additions of organic residues increase macrofauna populations, but have little effect on their diversity (Mando, 1998; Ayuke et al., 2003; Ou'edraogo et al., 2006), our study has demonstrated that conservation agriculture and medium to long-term application of organic residues can enhance the richness and abundance of soil fauna, which can in turn promote their activity, hence important soil functions like organic matter retention, stable aggregation and water infiltration (Castellanos-Navarrete et al., 2012; Paul et al., 2015). We speculate that higher soil fauna taxonomic richness in the medium and long-term trials could be due to longterm build-up of soil organic matter as food for the soil fauna groups. Studies conducted by Ayuke et al. (2009, 2011a) showed that earthworm taxonomic richness was higher in high carbon soils than in low carbon soils and this was attributed to longterm application of the various organic amendments across the long-term trials that resulted in corresponding build-up of soil organic matter. The relatively lower macrofauna abundance in the long-term trial of Nyabeda could be attributed to removal of 
crop residues during soybean planting, which possibly reversed the gains of CA that could otherwise promoted soil organic matter build-up thus food source for the soil fauna. Application of agrochemicals (e.g., pesticides and herbicides) could have also affected the soil organisms as these have been shown to directly affect the organisms through toxicity or indirectly by altering habitat structure and food chain (Gianessi, 2010; Isenring, 2010).

The soil fauna invertebrate community responses to the environmental (soil parameters) changes induced by land management practices and associated ecosystem disturbance reinforce the benefits of conservation agriculture and associated practices (e.g., the use of organic inputs). Soil invertebrates are important determinants of soil chemical and physical characteristics. As such, their potential beneficial role in biodegradation and humification of organic residues, SOM incorporation and soil aggregation in agricultural soils is well-established (Bossuyt et al., 2005; Pulleman et al., 2005a,b; Coq et al., 2007; Fonte et al., 2009; Ayuke et al., 2011b; Brussaard, 2012; Kihara et al., 2015). In view of this, we reiterate that knowledge such as of this study, that demonstrate impact of management practices among them tillage, organic resource use, crop rotation and mixed cropping, and application of inorganic fertilizers on soil fauna is important in enhancing ecosystem functioning and environmental sustainability.

\section{CONCLUSIONS}

This study assessed how conservation agriculture, and application of organic or inorganic inputs and cropping system, affected soil fauna richness and abundance. Results showed that: (1) Conservation agriculture enhances soil macrofauna taxonomic richness and mesofauna abundance than conventional agriculture, and that with addition of residues, both diversity and abundance are enhanced, both under CA and CT, (2) Rotation and mixed cropping (intercropping) such as maize legume systems, and sole maize systems coupled with organic residue addition are best bet practices that promote soil fauna diversity and abundance, and (3) Long-term addition of organic residues also enhances soil fauna diversity and abundance more than medium-term addition of organic residues.

\section{REFERENCES}

Anderson, J. M., and Ingram, J. S. I. (1993). Tropical Soil Biology and Fertility: A Handbook of the Methods, 2nd Edn. Wallingford: C.A.B. International.

Ayuke, F. O. (2000). Diversity, Abundance and Function of Soil Invertebrate Fauna in Relation in Relation to Quality of Organic Residues. M. Phil thesis of Moi University. Eldoret: Moi University.

Ayuke, F. O., Brussaard, L., Vanlauwe, B., Six, J., Lelei, D. K., Kibunja, C., et al. (2011a). Soil fertility management: impacts on soil macrofauna, soil aggregation and soil organic matter allocation. Appl. Soil Ecol. 48, 53-62. doi: 10.1016/j.apsoil.2011. 02.001

Ayuke, F. O., Karanja, N. K., Muya, E. M., Musombi, B. K., Mungatu, J., and Nyamasyo, G. H. N. (2009). Macrofauna diversity and abundance across different land use systems in Embu, Kenya. J. Trop. Subtrop. Agroecosyst.
Given the numerous challenges faced by smallholder farmers of SSA in the adoption of CA, who in most cases rarely practice all the three CA principles simultaneously, we propose a further study that will determine how each of the CA components (tillage, organic inputs and cropping systems and their interactions affect soil fauna diversity and abundance.

\section{DATA AVAILABILITY}

The datasets generated for this study can be found in Supplementary Tables uploaded in the site.

\section{AUTHOR CONTRIBUTIONS}

FA carried out the field activities, data analysis, and write up of the manuscript. JK financed the research activities through SIMLESA II project. $\mathrm{He}$ is the manager of the Nyabeda trial and also participated in the write up of the manuscript. GA managed the Kakamega medium-term trial and also contributed in the data generation and write up of the manuscript. AM managed the Embu medium-term trials also contributed in the data generation and write up of the manuscript.

\section{ACKNOWLEDGMENTS}

This study was supported by CIAT through funding from CIMMYT (SIMLESA II project) for the Eastern Kenya sites and from BMZ for the western Kenya sites. We sincerely thank Scientists and technical staff of Kenya Agricultural and Livestock Research Organization (KALRO), Embu and Kakamega for facilitating data collection, and IITA, Nairobi for availing laboratory equipment during taxonomic analyses of the fauna samples collected.

\section{SUPPLEMENTARY MATERIAL}

The Supplementary Material for this article can be found online at: https://www.frontiersin.org/articles/10.3389/fenvs. 2019.00097/full\#supplementary-material

11, 371-384. Available online at: http://www.revista.ccba.uady.mx/ojs/index. php/TSA/article/view/410

Ayuke, F. O., Pulleman, M. M., Vanlauwe, B., de Goede, R. G. M., Six, J., Csuzdi, C., et al. (2011b). Agricultural management affects earthworm and termite diversity across humid to semi-arid tropical zones. Agric. Ecosyst. Environ. 148, 148-154. doi: 10.1016/j.agee.2010.11.021

Ayuke, F. O., Rao, M. R., Swift, M. J., and Opondo-Mbai, M. L. (2003). Impact of soil fertility management strategies on diversity and populations of soil macrofauna in agroecosystem. Special Issue: sustainable use of land resources to alleviate poverty in the new millenium. East Afr. Agric. Forest. J. 69, 131-137. doi: 10.4314/eaafj.v69 i2.1814

Bates, D., Machler, M., Bolker, B. M., and Walker, S. C. (2015). Fitting linear mixed effects models using Ime4. J. Stat. Softw. 67, 1-48. doi: 10.18637/jss. v067.i01 
Beare, M. H., Reddy, M. V., Tian, G., and Scrivasta, S. C. (1997). Agricultural intensification, soil biodiversity and agroecosystem function in the tropics: the role of decomposer biota. Appl. Soil Ecol. 6, 87-108. doi: 10.1016/S0929-1393(96)00150-3

Bignell, D. E., Constantino, R., Csuzdi, C., Karyanto, A., Konate, S., Louzada, J., et al. (2008). "Macrofauna," in A Handbook of Tropical Soil Biology: Sampling and Characterization of Below-ground Biodiversity, eds F. M. S. Moreira, J. E. Huising, and D. Bignell (Aldershot: Earthscan), 43-83.

Bossuyt, H., Six, J., and Hendrix, P. F. (2005). Protection of soil carbon by microaggregates within earthworm casts. Soil Biol. Biochem. 37, 251-258. doi: 10.1016/j.soilbio.2004.07.035

Brussaard, L. (2012). "Ecosystem services provided by the soil biota," in Soil Ecology and Ecosystem Services, eds D. H. Wall, R. D. Bardgett, V. Behan-Pelletier, J. E. Herrick, T. H. Jones, K. Ritz, J. Six, D. R. Strong, and W. H. van der Putten (Oxford, UK: Oxford University Press), 45-58.

Brussaard, L., Caron, P., Campbell, B. M., Lipper, L., Mainka, S., Rabbinge, R., et al. (2010). Reconciling biodiversity conservation and food security: scientific challenges for a new agriculture. Curr. Opin. Environ. Sustainability 2, 34-42. doi: 10.1016/j.cosust.2010. 03.007

Cao, Y., Williams, D., and Williams, N. E. (1999). Data transformation and standardization in the multivariate analysis of river water quality. Ecol. Appl. 9, 669-677. doi: 10.1890/1051-0761(1999)009[0669:DTASIT] 2.0.CO;2

Castellanos-Navarrete, A., Rodríguez-Aragonés, C., de Goede, R. G. M., Kooistra, M. J., Sayre, K. D., Brussaard, L., et al. (2012). Earthworm activity and soil structural changes under conservation agriculture in Mexico. Soil Till. Res. 123, 61-70. doi: 10.1016/j.still.2012.03.011

Coq, S., Barthes, B. G., Oliver, R., Rabary, B., and Blanchart, E. (2007). Earthworm activity affects soil aggregation and organic matter dynamics according to the quality and localization of crop residues-An experimental study (Madagascar). Soil Biol. Biochem. 39, 2119-2128. doi: 10.1016/j.soilbio.2007.03.019

Curry, J. P. (2004). "Factors affecting the abundance of earthworms in soils," in Earthworm Ecology, 2nd Edn, ed C. A. Edwards (Boca Raton, NY: CRC Press), 91-113. doi: 10.1201/9781420039719.pt3

Dangerfield, J. M. (1993). "Characterization of soil fauna communities," in Report on Characterization of an Experimental Field in KARI Farm, Muguga, Kenya, eds M. R. Rao and R. J. Scholes (Nairobi: ICRAF), 51-67.

Derpsch, R., Friedrich, T., Kassam, A., and Hongwen, L. (2010). Current status of adoption of no-till farming in the world and some of its main benefits. Int. J. Agric. Biol. Eng. 3, 1-25. doi: 10.3965/j.issn.1934-6344.2010.01.001-025

Ekschmitt, K., Wolters, V., and Weber, M. (1997). "Spiders, carabids and Staphylinids: the ecological potential of predatory microarthropods," in Fauna in Soil Ecosystems: Recycling Processes, Nutrient Fluxes and Agricultural Production, ed G. Benckiser (Newyork, NY: Mercel Dekker), 307-362.

FAO. (1989). Forestry and Food Security. FAO Forestry Paper.

FAO-UNESCO. (1997). Soil Map of the Worlds. Rome.

Field, A. (2005). Discovering Statistics Using SPSS, 2nd Edn. London: Sage Publications.

Fonte, S. J., Winsome, T., and Six, J. (2009). Earthworm populations in relation to soil organic matter dynamics and management in California tomato cropping systems. Appl. Soil Ecol. 41, 206-214. doi: 10.1016/j.apsoil.2008.10.010

Garnett, T., Appleby, M. C., Balmford, A., Bateman, I. J., Benton, T. G., Bloomer, P., et al. (2013). Sustainable intensification in agriculture: premises and policies. Science 341, 33-34. doi: 10.1126/science. 1234485

Genstat 17.1. (2015). Genstat Release, 17th Edn. Hemel Hempstead, UK: VSN International Ltd.

Gianessi, L. P. (2010). Pesticide Use and Biodiversity Conservation on Farms. Washington, DC: CropLife Foundation.

Isaac, R. A., and Johnson, W. C. Jr. (1998). "Elemental determination by inductively coupled plasma atomic emission spectrometry," in Handbook of Reference Methods for Plant Analysis, ed Y. P. Kalra (Boca Raton, FL: CRC Press), 165-170. doi: 10.1201/97814200493 98.ch21

Isenring, R. (2010). Pesticides and the Loss of Biodiversity: How Intensive Pesticide Use Affects Wildlife Populations and Species Diversity. Pesticide Action Network Europe.
Jaetzold, R., Schemidt, H., Hornetz, B., and Shisanya, C. (2006). Farm Management Handbook of Kenya, Vol. II/A, Natural Conditions and Farm Management, 2nd $E d n$. Nairobi: Ministry of Agriculture in cooperation with German Agency for Technical Cooperation (GTZ).

Jaetzold, R., Schmidt, H., Hornetz, B., and Shisanya, C. (2007). Farm Management Hardbook of Kenya, Vol. II/C, Natural Conditions and Farm Management, 2nd $E d n$. Nairobi: Ministry of Agriculture in cooperation with the German Agency for Technical Co-operation (GTZ).

Jongman, R. H. G., Ter Braak, C. J. F., and Van Tongeren, O. F. R. (2005). Data Analysis in Community and Landscape Ecology. Cambridge: Cambridge University Press.

Karanja, N. K., Ayuke, F. O., Muya, E. M., Musombi, B. K., and Nyamasyo, G. H. N. (2009). Soil macrofauna community structure across land use systems of Taita, Kenya. J. Trop. Subtrop. Agroecosyst. 11, 385-396. Available online at: http:// www.revista.ccba.uady.mx/ojs/index.php/TSA/article/view/411

Karanja, N. K., Ayuke, F. O., and Swift, M. J. (2006). Organic resources quality and Soil fauna: their role on the microbial biomass, decomposition and nutrient release patterns in Kenyan soils. J. Trop. Subtrop. Agroecosyst. 6, 73-86.

Kihara, J., Martius, C., Amelung, W., Bationo, A., Thuita, M., Lesueur, D., et al. (2012). Soil aggregation and total bacteria and fungi diversity in various tillage systems of sub-Humid and Semi-Arid Kenya. Appl. Soil Ecol. 58, 12-20. doi: 10.1016/j.apsoil.2012.03.004

Kihara, J., Martius, C., and Bationo, A. (2015). Crop residue disappearance and macrofauna activity in sub-humid western Kenya. Nutr. Cycl. Agroecosyst. 102, 101-111. doi: 10.1007/s10705-0149649-2

Kuznetsova, A., Brockhoff, P. B., and Christensen, R. H. B. (2014). lmerTest: Tests for Random and fixed Effects for Linear Mixed Effect Models (lmer Objects of lme4 Package). R Package Version 2.0-6. Available online at: http://CRAN.Rproject.org/package $=$ lmerTest

Lal, R. (2007). Constraints to adopting no-till farming in developing countries. Soil Till. Res. 94, 1-3. doi: 10.1016/j.still.2007.02.002

Lowe, C. N., and Butt, K. R. (2002). Influence of organic matter on earthworm production and behaviour: a laboratory-based approach with application for soil restoration. Eur. J. Soil Biol. 38, 173-176. doi: 10.1016/S1164-5563(02)01141-X

Mando, A. (1998). Soil-dwelling termites and mulches improve nutrient release and crop performance on Sahelian crusted soil. Arid. Soil Res. Rehab. 12, 153-164. doi: 10.1080/15324989809381505

Mehlich, M. (1984). Mehlichs-3 soil test extractant: a modification of the Mehlich 2 extractant. Commun. Soil Sci. Plant Anal. 15, 1409-1416. doi: 10.1080/00103628409367568

Micheni, A. N., Njeru, M. J., Kanampiu, F. K., Mburu, D. M., Mugai, E. N., and Kitonyo, O. M. (2016). Response of soil microfauna to tillage methods and cropping systems in Humic Nitisols of Eastern Kenya. Afr. J. Hort. Sci. 10, 21-33. Available online at: http://hakenya.net/ajhs/index.php/ajhs/article/ view/158

Nhamo, N. (2007). The Contribution of Different Fauna Communities to Improved Soil Health: A Case of Zimbabwean Soils Under Conservation Agriculture. Thesis Dissertation. Bonn: Rheinischen Friedrich-Wilhelms-Universitat.

Ou'edraogo, E., Mando, A., and Brussaard, L. (2006). Soil macrofauna affect crop nitrogen and water use efficiencies in semi-arid West Africa. Eur. J. Soil Biol. 42, 275-277. doi: 10.1016/j.ejsobi.2006.07.021

Paul, B. K., Vanlauwe, B., Ayuke, F. O., Gassnerc, A., Hoogmoed, M., Hurissoa, T. T., et al. (2013). Medium-term impact of tillage and residue management on soil aggregate stability, soil carbon and crop productivity. Agric. Ecosyst. Environ. 164, 14-22. doi: 10.1016/j.agee.2012.10.003

Paul, B. K., Vanlauwe, B., Hoogmoed, M., Hurisso, T. T., Ndabamenye, T., Terano, Y., et al. (2015). Exclusion of soil macrofauna did not affect soil quality but increased crop yields in a sub-humid tropical maizebased system. Agric. Ecosyst. Environ. 208, 75-85. doi: 10.1016/j.agee.2015. 04.001

Pulleman, M. M., Six, J., Uyl, A., Marinissen, J. C. Y., and Jongmans, A. G. (2005b). Earthworms and management affect organic matter incorporation and microaggregate formation in agricultural soils. Appl. Soil Ecol. 29, 1-15. doi: 10.1016/j.apsoil.2004.10.003

Pulleman, M. M., Six, J., van Breeman, N., and Jongmans, A. G. (2005a). Soil organic matter distribution as affected by agricultural 
management and earthworm activity. Eur. J. Soil Sci. 56, 453-467. doi: $10.1111 /$ j.1365-2389.2004.00696.x

Southwood, T. R. E. (1995). Ecological Methods: With Particular Reference to the Study of Insect Population, 2nd Edn. London: Chapman and Hall.

Stinner, B. R., and House, G. F. (1990). Arthropods and other invertebrates in conservation tillage. Ann. Rev. Entomol. 35, 299-318. doi: 10.1146/annurev.en.35.010190.001503

Swift, M. J., and Bignell, D. (2001). "Standard methods for assessment of soil biodiversity and land use practice," in ASB Lecture Note $6 B$ (Bogor).

Undheim, E. A. B., and King, G. F. (2011). On the venom system of centipedes Chilopoda, a neglected group of soil animals. Toxicon 57, 512-524. doi: 10.1016/j.toxicon.2011.01.004

Vanlauwe, B., Descheemaeker, K., Giller, K. E., Huising, J., Merckx, R., Nziguheba, G., et al. (2015). Integrated soil fertility management in sub-Saharan Africa: unravelling local adaptation. Soil 1, 491-508. doi: 10.5194/soil-1-491-2015

Vanlauwe, B., Wendt, J., Giller, K. E., Corbeels, M., Gerard, B., and Nolte, C. (2014). A fourth principle is required to define Conservation Agriculture in subSaharan Africa: the appropriate use of fertilizer to enhance crop productivity. Field Crops Res. 155, 10-13. doi: 10.1016/j.fcr.2013.10.002
Wall, P. C. (2007). Tailoring conservation agriculture to the needs of small farmers in developing countries. J. Crop Improv. 19, 137-155. doi: 10.1300/J411v19n01_07

Ziesche, T. M., and Roth, M. (2008). Influence of environmental parameters on small-scale distribution of soil-dwelling spiders in forests: what makes the difference, tree species or microhabitat? For. Ecol. Manag. 255, 738-752. doi: $10.1016 /$ j.foreco.2007.09.060

Conflict of Interest Statement: The authors declare that the research was conducted in the absence of any commercial or financial relationships that could be construed as a potential conflict of interest.

Copyright (C) 2019 Ayuke, Kihara, Ayaga and Micheni. This is an open-access article distributed under the terms of the Creative Commons Attribution License (CC BY). The use, distribution or reproduction in other forums is permitted, provided the original author(s) and the copyright owner(s) are credited and that the original publication in this journal is cited, in accordance with accepted academic practice. No use, distribution or reproduction is permitted which does not comply with these terms. 